\title{
Epidemiology of chronic obstructive pulmonary disease: a literature review
}

This article was published in the following Dove Press journal:

International Journal of COPD

19 July 2012

Number of times this article has been viewed

\section{Catherine E Rycroft ${ }^{1}$ \\ Anne Heyes' \\ Lee Lanza ${ }^{2}$ \\ Karin Becker ${ }^{3}$}

'Market Access and Outcomes Strategy, RTI Health Solutions, Manchester, United Kingdom; ${ }^{2}$ Epidemiology, RTI Health Solutions, Waltham, MA, USA; ${ }^{3}$ Global Health Economics and Outcomes Research, Boehringer Ingelheim $\mathrm{GmbH}$, Ingelheim, Germany

\section{Video abstract}

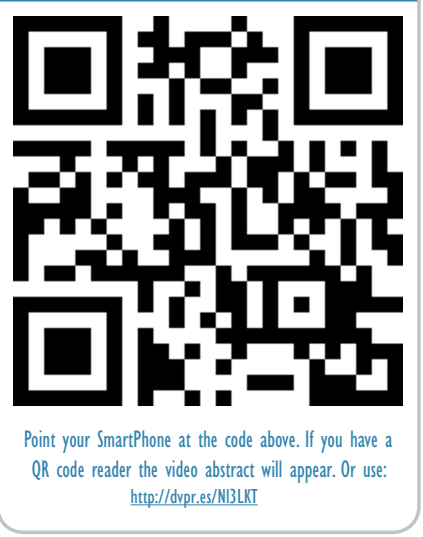

Correspondence: Catherine E Rycroft RTI Health Solutions, 2nd Floor, The Pavilion, Towers Business Park, Wilmslow Road, Didsbury, Manchester, M20 2LS, UK

Tel +44 0I6I 4476022

Fax +44 016I 4348232

Email crycroft@rti.org
Abstract: The aim of this study is to quantify the burden of chronic obstructive pulmonary disease (COPD) - incidence, prevalence, and mortality - and identify trends in Australia, Canada, France, Germany, Italy, Japan, The Netherlands, Spain, Sweden, the United Kingdom, and the United States of America. A structured literature search was performed (January 2000 to September 2010) of PubMed and EMBASE, identifying English-language articles reporting COPD prevalence, incidence, or mortality. Of 2838 articles identified, 299 full-text articles were reviewed, and data were extracted from 133 publications. Prevalence data were extracted from 80 articles, incidence data from 15 articles, and mortality data from 58 articles. Prevalence ranged from $0.2 \%-37 \%$, but varied widely across countries and populations, and by COPD diagnosis and classification methods. Prevalence and incidence were greatest in men and those aged 75 years and older. Mortality ranged from 3-111 deaths per 100,000 population. Mortality increased in the last 30-40 years; more recently, mortality decreased in men in several countries, while increasing or stabilizing in women. Although COPD mortality increased over time, rates declined more recently, likely indicating improvements in COPD management. In many countries, COPD mortality has increased in women but decreased in men. This may be explained by differences in smoking patterns and a greater vulnerability in women to the adverse effects of smoking.

Keywords: COPD, incidence, literature review, mortality, prevalence

\section{Introduction}

Chronic obstructive pulmonary disease (COPD) is a chronic respiratory disease characterized by a decline in lung function over time and accompanied by respiratory symptoms, primarily dyspnea, cough, and sputum production. ${ }^{1}$ Consequently, COPD is associated with a significant economic burden, including hospitalization, work absence, and disability. ${ }^{1}$ Current data suggest that COPD mortality is increasing, and by 2020 , COPD is predicted to be the third-leading cause of death worldwide. ${ }^{2}$

The severity of COPD can be determined and classified by different methods. Incidence and prevalence estimates differ greatly, depending on the methods used for diagnosis and classification. It is important to understand the true epidemiology of COPD to monitor trends over time and to determine the effectiveness of potential treatments or preventive measures.

The objectives of this study were to conduct a structured, comprehensive literature review to identify articles on the epidemiology of COPD in eleven developed countries (Australia, Canada, France, Germany, Italy, Japan, The Netherlands, Spain, Sweden, the United Kingdom, and the United States of America [USA]); quantify the burden of illness of COPD in terms of incidence, prevalence, and mortality; identify trends in 
these data over time; and identify any trends regarding age, sex, and/or disease severity.

\section{Methods}

A structured and comprehensive search of medical literature indexed in the electronic PubMed (http://www.ncbi.nlm.nih. gov/sites/entrez) and EMBASE (http://www.embase.com/ info/accessing-embase) databases was conducted using a detailed search strategy with a combination of free-text search terms and medical subject headings. Search terms included terms related to COPD, chronic bronchitis, and pulmonary emphysema, and terms for epidemiology including incidence, prevalence, rate of mortality, and risk of dying (see Table S1). The search was restricted to articles in English published between January 2000 and September 2010.

Articles identified from each literature search were screened in two phases by one reviewer using predefined inclusion and exclusion criteria. Phase 1 involved reviewing all titles and abstracts to determine whether to include or exclude them, and Phase 2 involved reviewing the full text of the articles identified in Phase 1 to determine their inclusion or exclusion for data extraction.

Articles were included if they reported incidence, prevalence, and/or mortality in COPD, or trends in such data for at least one of the countries of interest (Australia, Canada, France, Germany, Italy, Japan, The Netherlands, Spain, Sweden, the UK, or the USA). Articles were excluded if they met at least one of the following exclusion criteria; that is, if the article:

- was a comment, an editorial, a letter, a case report, or a clinical trial;

- did not report data specifically for COPD;

- did not report data on incidence, prevalence, and/or mortality, or trends in such data;

- was not concerned with any of the countries of interest;

- focused on a limited population, including studies in small numbers of patients, patients in very limited subpopulations, such as patients who were hospitalized, and patients with an existing condition that increased their risk for $\mathrm{COPD}$, or studies that investigated risk factors for COPD;

- reported a study conducted in a single site, clinic, hospital, or city;

- focused on comorbidities in patients with COPD; or reported incidence, prevalence, or mortality associated specifically with exacerbations of COPD, not COPD overall;

- reported incidence or prevalence estimates from a model (ie, the article was not the primary data source);
- reported on design of a study but did not report results;

- was a duplicate of an article that had been previously identified.

Inclusion and exclusion processes were documented fully, and a Preferred Reporting Items for Systematic Reviews and Meta-Analyses (PRISMA) flow chart was completed. ${ }^{3}$

Relevant data were extracted from the included articles into evidence tables for each country. Quality-control checks verifying the summarized data against the source articles to confirm correct extraction were performed by an independent quality-control specialist on all extracted data.

\section{Results}

\section{Summary of identified studies}

The PRISMA flow chart (Figure 1) presents the two-phase screening approach, and the number of articles included, and excluded at each phase. From the initial database searches, 2838 unique articles were identified of which 299 articles were retrieved for full-text evaluation. Of those, 133 were included for data extraction.

Overall, the greatest number of relevant articles was identified for the USA $(n=49)$, Sweden $(n=19)$, and Canada $(n=12)$ (see Table S2). A total of 19 articles were identified that reported data for more than one country ("multicountry" studies). Most articles (80) focused on prevalence of COPD; another 15 articles reported incidence, and 58 reported mortality associated with COPD (Table S2). Twelve articles reported trends in incidence and/or prevalence, whereas 25 articles reported trends in mortality.

\section{Prevalence}

The reported prevalence of COPD ranged from $0.2 \%$ in Japan to $37 \%$ in the USA, but this varied widely across countries and populations, by diagnosis method, and by age group analyzed. Table 1 presents those studies that measured COPD by multiple methods within the same population to compare prevalence estimates resulting from different methods. Prevalence estimates varied according to the method of diagnosis and classification of COPD. ${ }^{4-7}$ When individuals were identified by spirometry, and classified using the 2001 Global Initiative for Chronic Obstructive Lung Disease (GOLD) criteria for COPD (forced expiratory volume in 1 second/ forced vital capacity $\left[\mathrm{FEV}_{1} / \mathrm{FVC}\right]<0.70$ ), a greater COPD prevalence was reported than when using other classification methods such as the British Thoracic Society (BTS), European Respiratory Society (ERS), American Thoracic Society (ATS) spirometric, or ATS clinical criteria. ${ }^{4-6,8,9}$ 


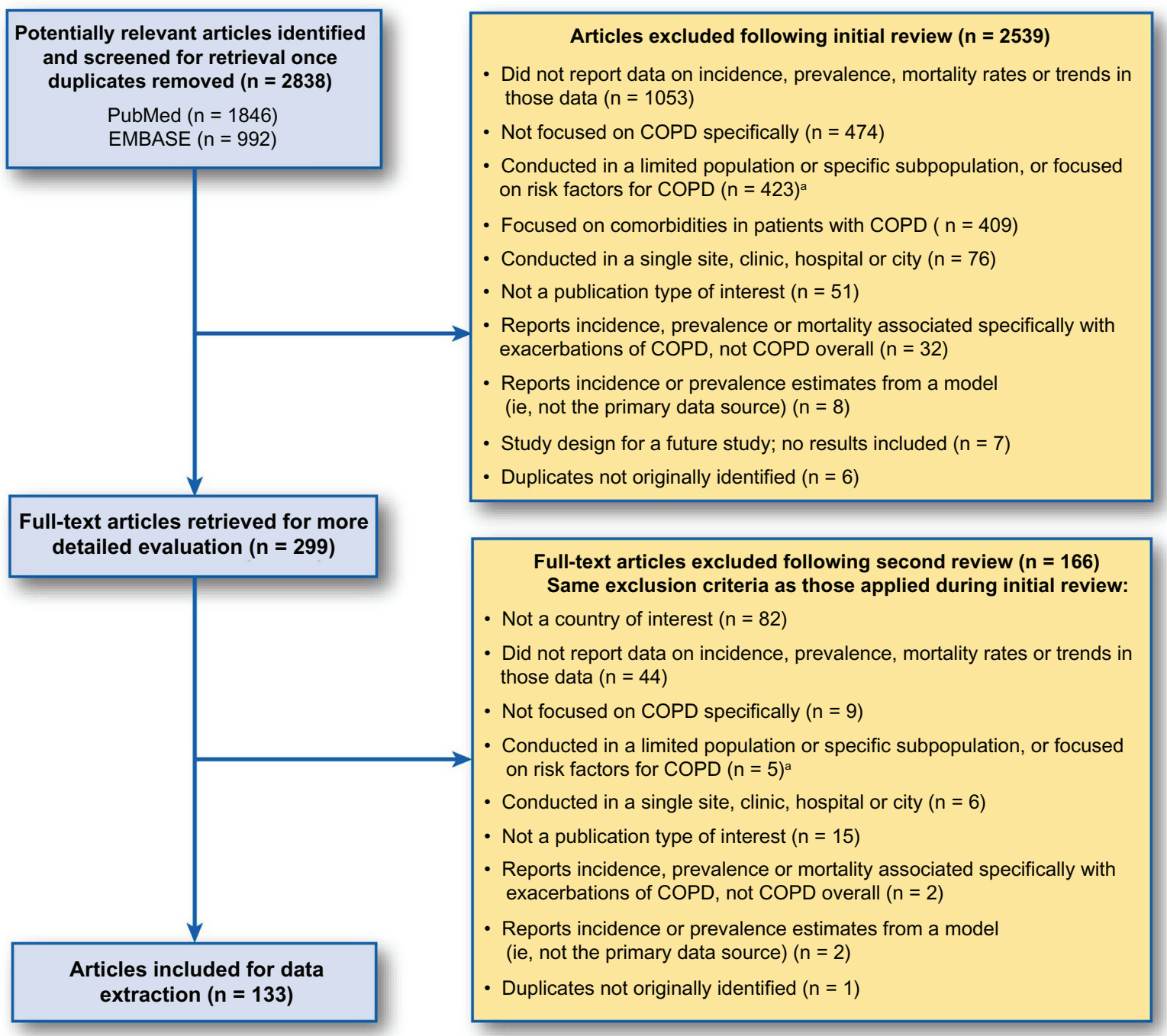

Figure I PRISMA flow diagram of the literature review.

Notes: ancludes studies in small numbers of patients, patients in very specific populations, patients who are hospitalized, patients with an existing condition that increases risk for COPD, and studies investigating risk factors for COPD.

Abbreviations: COPD, chronic obstructive pulmonary disease; PRISMA, Preferred Reporting Items for Systematic Reviews and Meta-Analyses.

This was supported by information from other studies that found that prevalence estimates by spirometry were higher than those estimated using methods based on symptoms (Table 1). ${ }^{5,6,10-16}$ Some multicountry studies reported similar findings when looking at data from several countries, reporting a greater prevalence of COPD diagnosed by spirometry compared with self-reporting (see Table 1).

COPD was more commonly reported in older populations and was most prevalent in adults aged 75 years and older. Overall, the studies showed that the prevalence of COPD has increased over time, although the rate of increase has declined in recent years, particularly among men.

Details of all studies providing prevalence data are given in Table S3 in the supplementary material.

\section{Incidence}

Table 2 presents a summary of the population-incidence data reported in the identified articles. The incidence of COPD varied greatly between countries, but it is difficult to compare estimates because they are reported in different units and over different lengths of time. In most of the studies, the incidence of COPD was greater in men than in women. ${ }^{17-21}$ The incidence of COPD was also greater in older individuals, particularly in those aged 75 years and older. ${ }^{15,21}$ Six articles reported trends in incidence over time for Australia, Canada, Sweden, and the USA. ${ }^{15,18,22-25}$ Although COPD incidence has increased over the last 20 years, within the last 10 years, there has been an overall decrease. Studies in Canada ${ }^{18}$ and the USA ${ }^{25}$ reported that trends in incidence over time were similar between men and women; however, in Australia, COPD incidence 


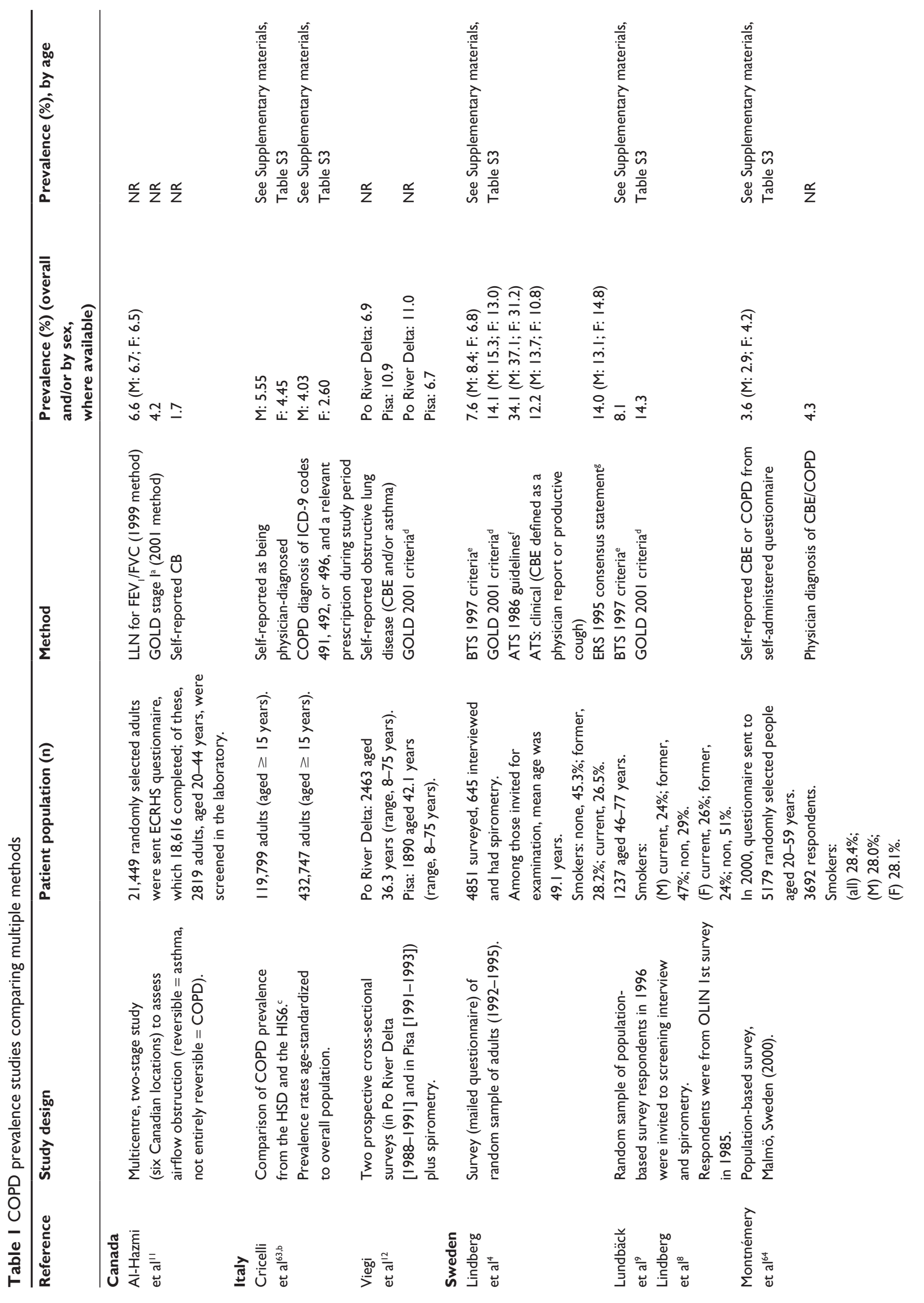




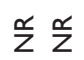
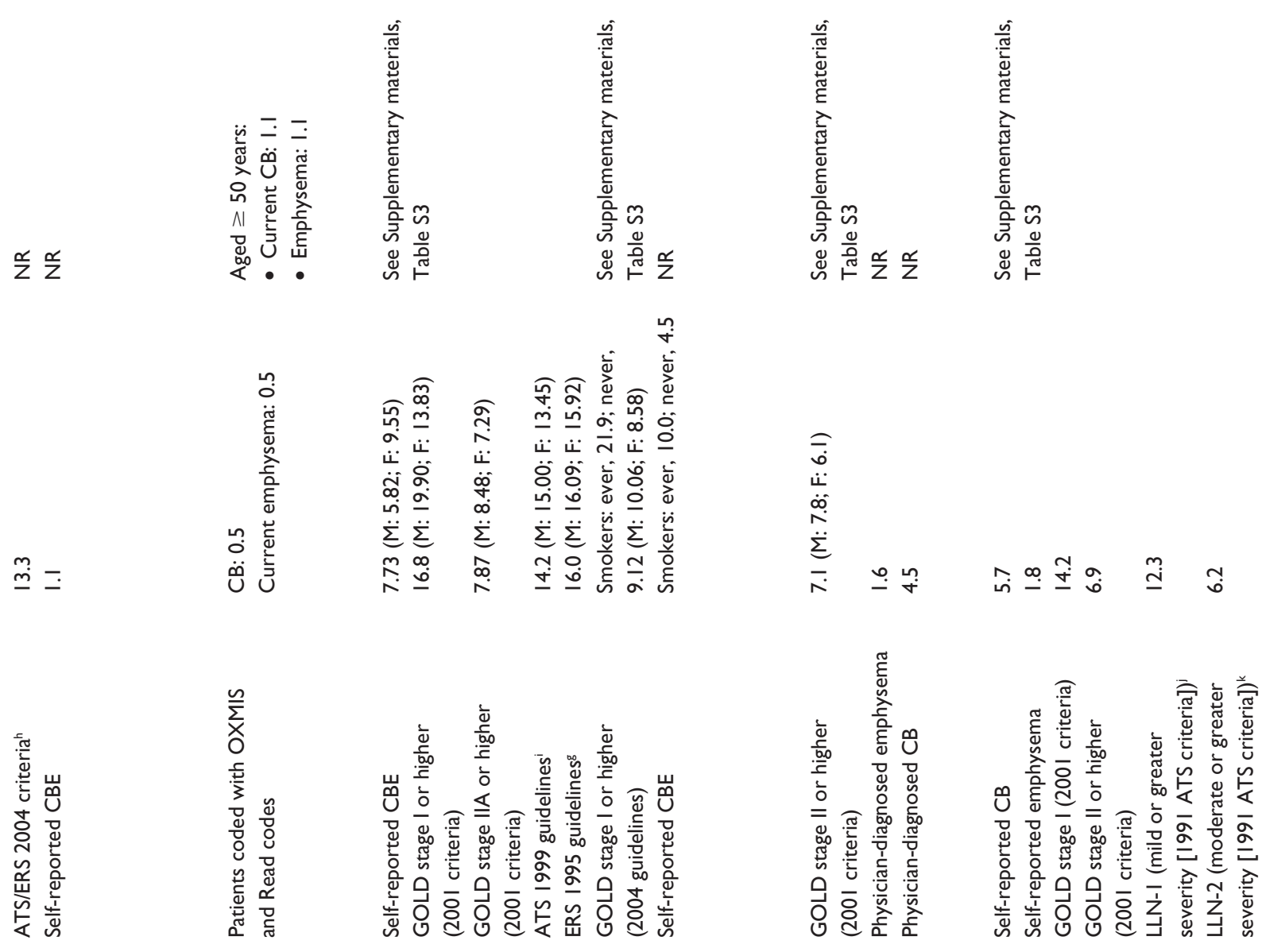

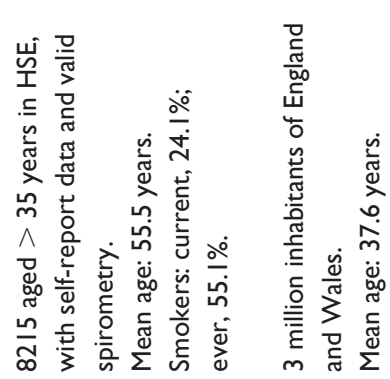
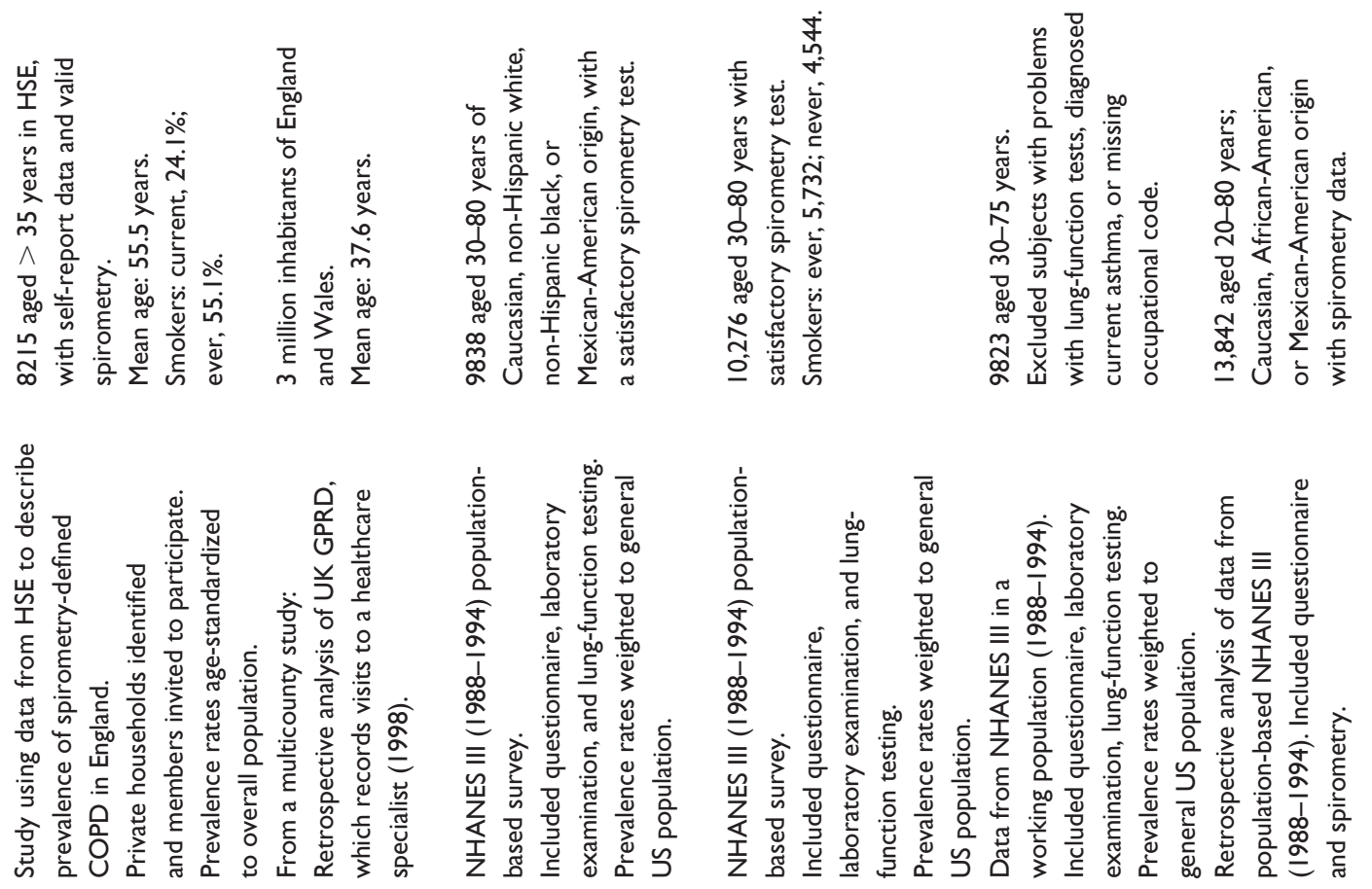

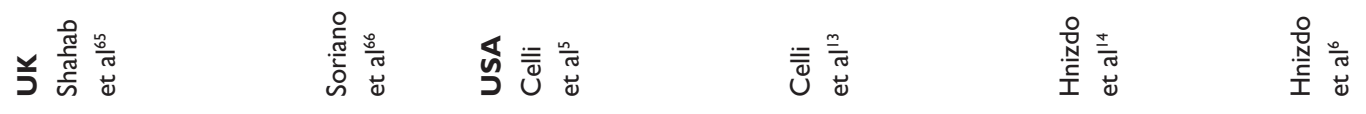




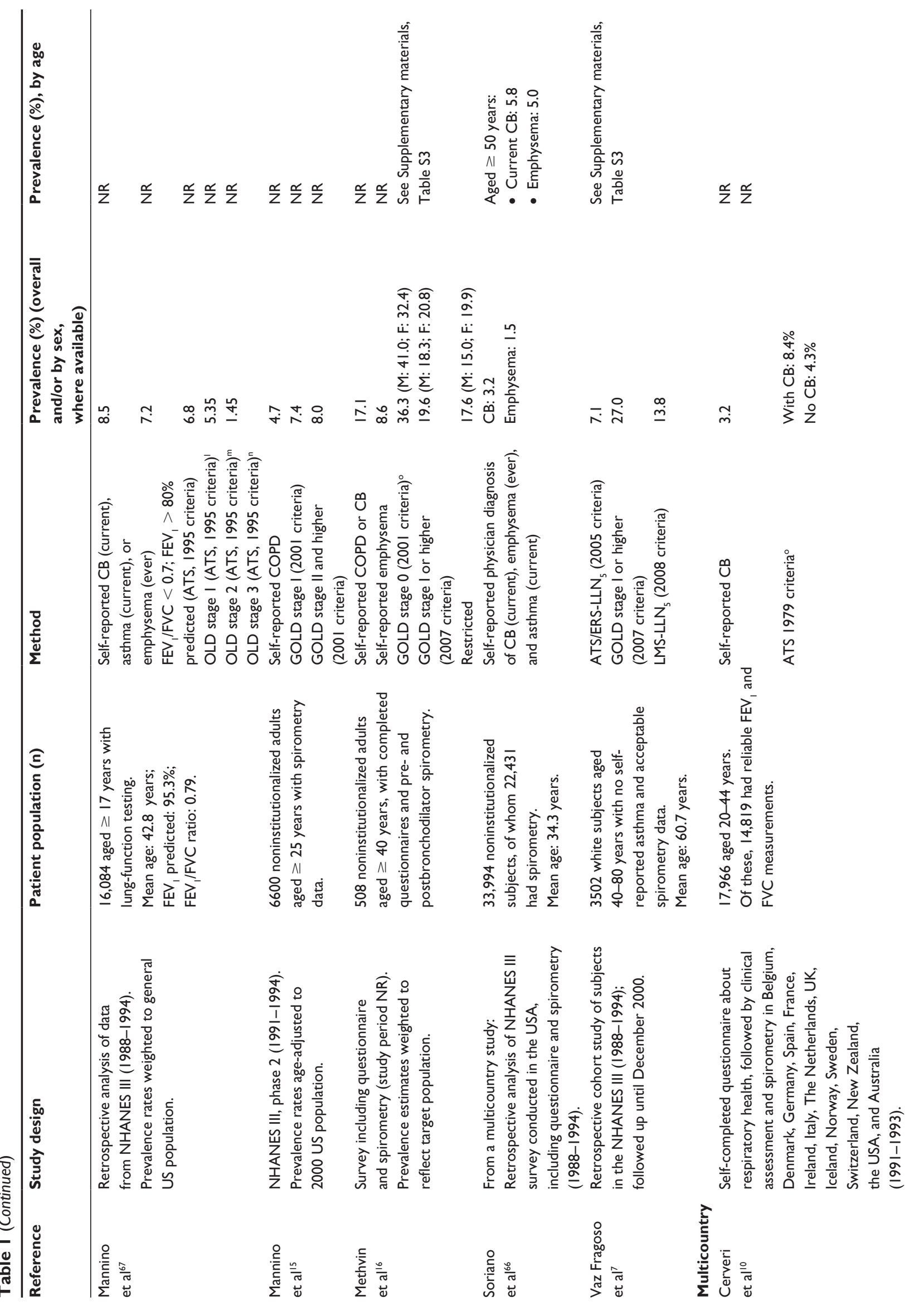




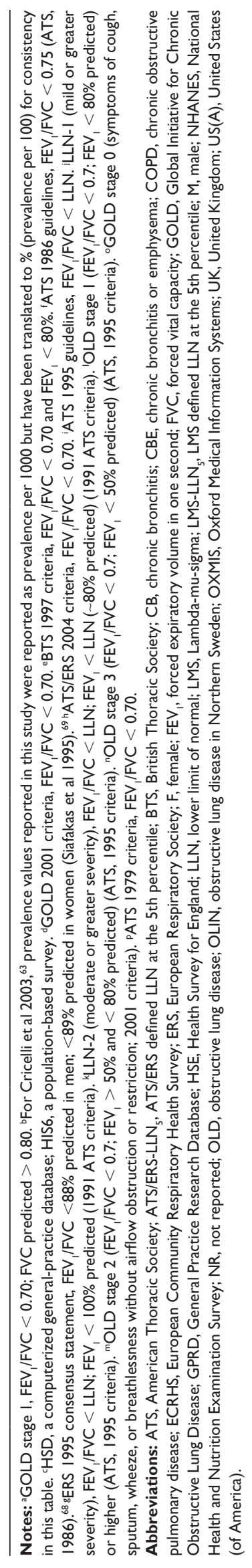

decreased in men between 1998 and 2003 but increased in women. ${ }^{22}$ Two articles, both conducted in Sweden as part of the Obstructive Lung Disease in Northern Sweden (OLIN) study, reported incidence rates in smokers (Table 2). ${ }^{20,26}$ These studies reported a two- to three-times greater incidence in smokers than nonsmokers when measured by spirometry, and assessed by GOLD or BTS criteria. ${ }^{20,26}$ One study also reported that COPD incidence in former smokers was more than double that in nonsmokers. ${ }^{26}$

\section{Mortality}

The 58 articles that presented mortality associated with COPD varied in the way they reported the data. Twenty-four articles reported the mortality rate within a group of patients with COPD, 14 reported the proportion of all deaths that could be attributed to COPD, and 21 articles reported overall mortality from COPD within the whole population.

Of the studies that reported mortality rates within patients with COPD, length of follow-up differed, which resulted in difficulties comparing studies. However, the one-year mortality rate of COPD (all severity stages) was reported in four studies and varied from $4.1 \%$ in patients aged 45 years and older, to $27.7 \%$ in patients aged $65-100$ years in Canada, ${ }^{18,27,28}$ and to $5.1 \%$ in patients aged $41-83$ years in Sweden. ${ }^{29}$

Between $2.3 \%$ and $8.4 \%$ of all deaths were caused by COPD, and this proportion was greater in men than women, ${ }^{30-32}$ and greatest in subjects aged $65-74$ years. ${ }^{33}$

Measuring the number of COPD deaths per whole population provides a true picture of the burden of COPD mortality within the population. The overall mortality rate varied between countries, ranging from 3-9 deaths per 100,000 population in Japan to 7-111 deaths per 100,000 population in the USA. In almost all these studies, COPD mortality was greater within the male population than within the female population ${ }^{15,34-45}$ and was greatest in elderly adults aged 75 years and older. ${ }^{15,35-38,43}$

Two studies were identified that reported deaths due to COPD as a proportion of deaths attributable to smoking: numbers ranged from $12.8 \%$ across several industrialized countries $^{46}$ to $20.9 \%$ in the USA. ${ }^{47}$ One study also reported that $19 \%-24 \%$ of all smoking-related deaths in women and $52 \%-54 \%$ of all smoking-related deaths in men resulted from COPD. ${ }^{48}$ One US study reported that mortality in a population of those who quit smoking was almost half of that in a population of individuals who switched from cigarette smoking to spit tobacco (49 versus 89 per 100,000 population). ${ }^{49}$ 


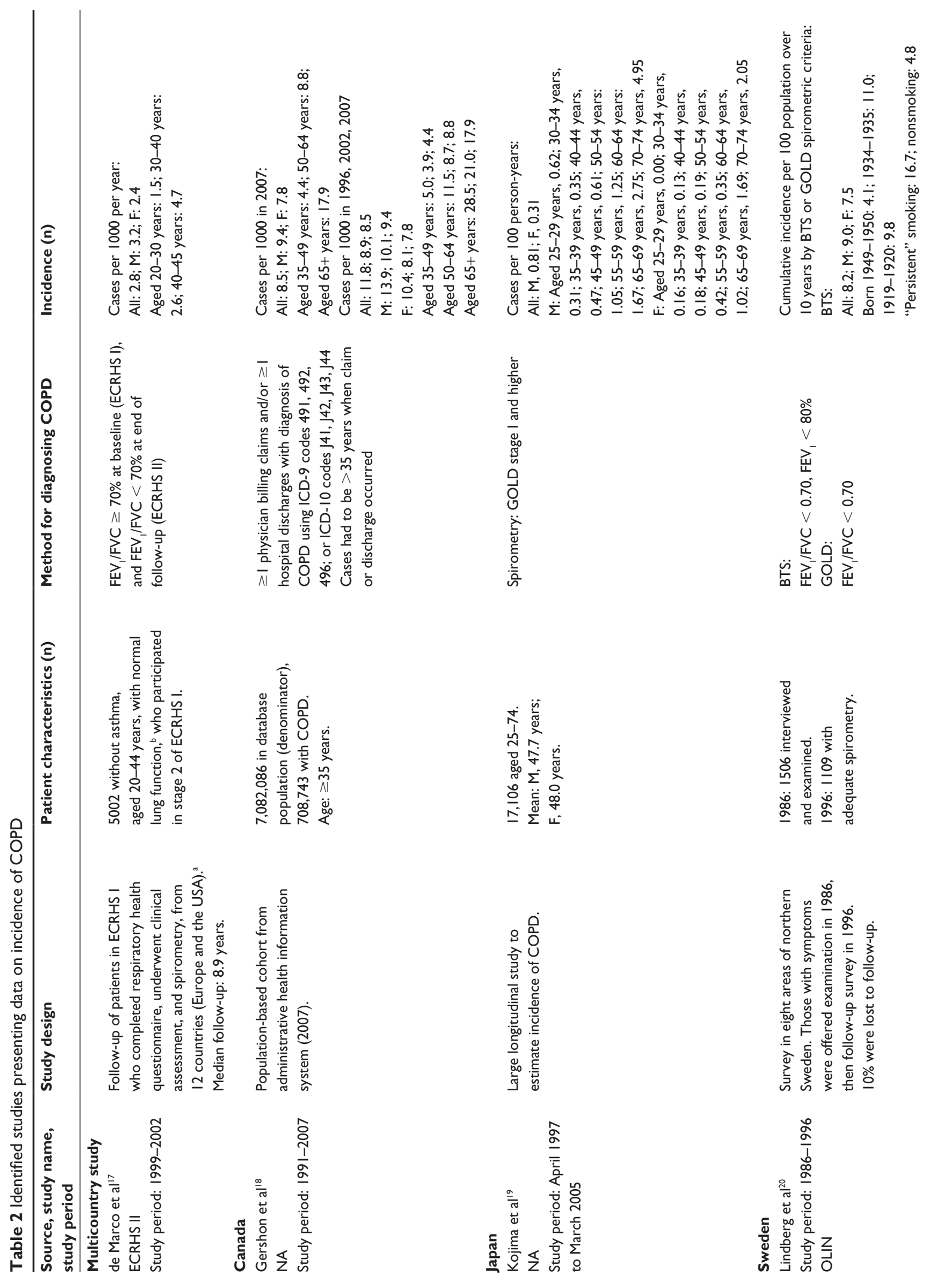



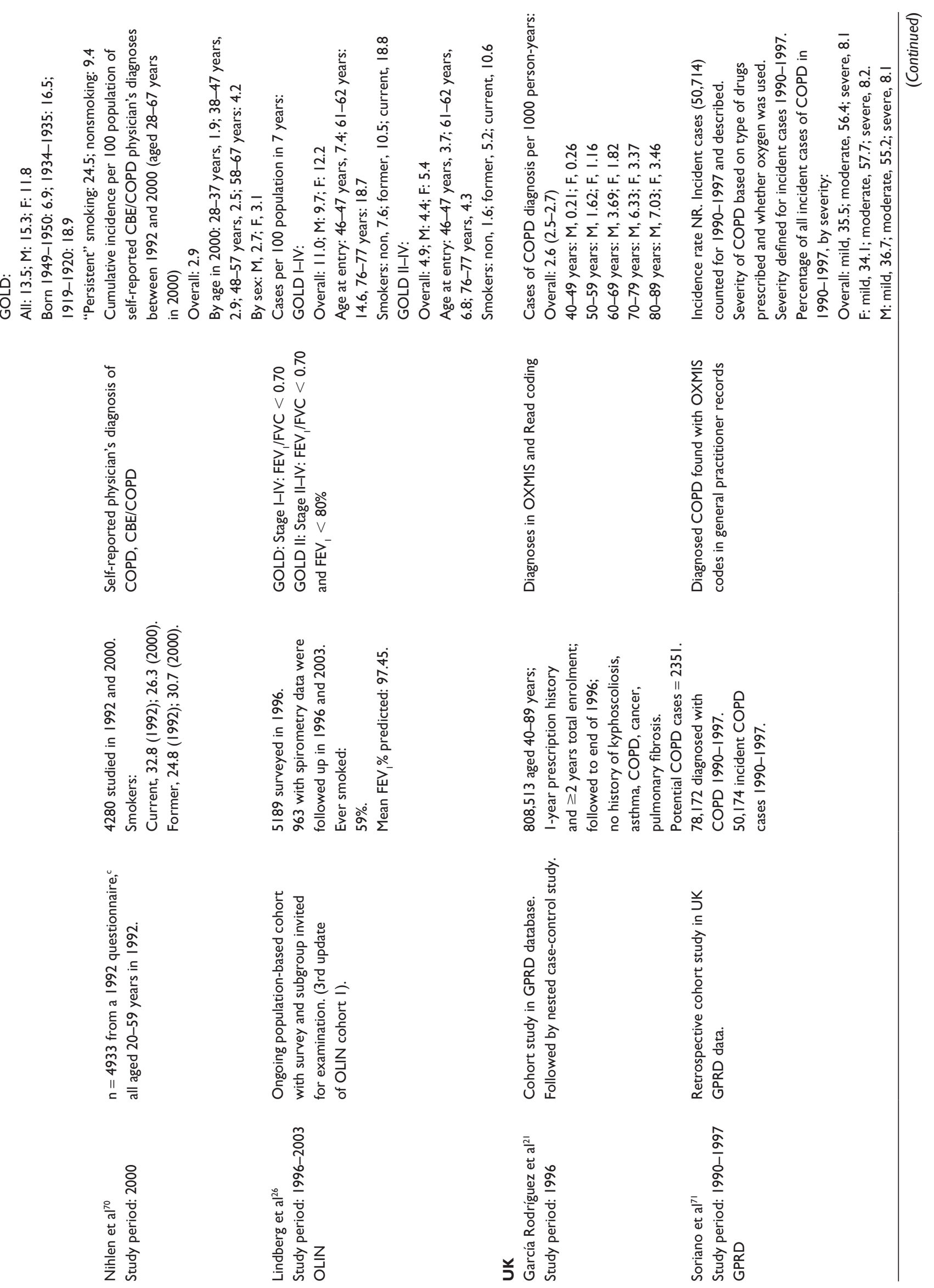


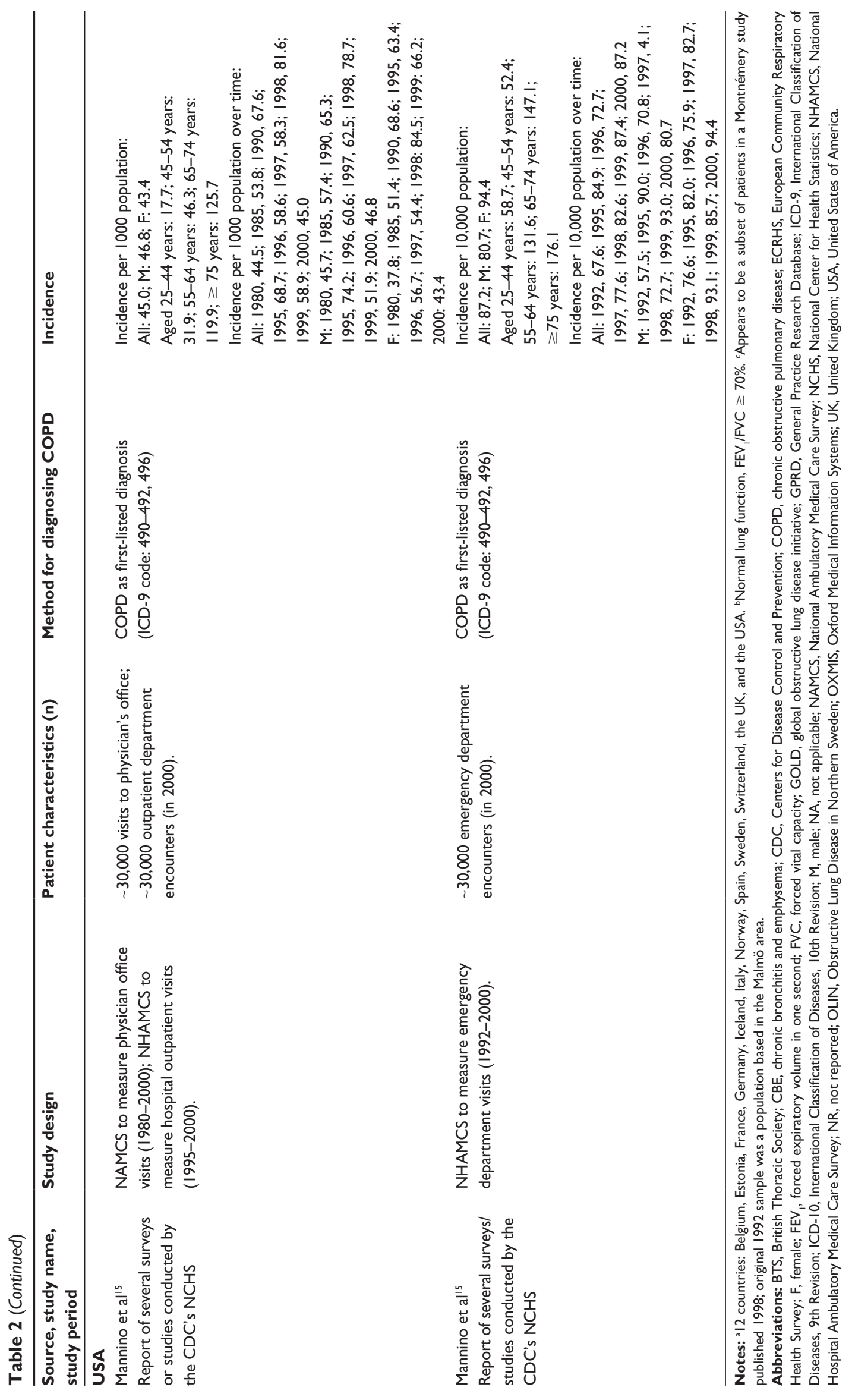




\section{Trends in mortality}

A total of 25 articles reported COPD mortality over different years to allow trends to be observed, 14 of which reported the changes in COPD mortality within the overall population. These included studies conducted in Australia (2), Canada (1), France (1), and the USA (10) (Table 3). Our literature review did not identify any articles reporting trends in mortality in Germany, Italy, Japan, The Netherlands, Spain, Sweden, or the UK. In general, the studies reported an overall increase in COPD mortality rates within the last 30-40 years, with a much greater increase in mortality in women compared with men. . $^{15,34,35,38,40,42,45}$ Some studies have indicated that more recently (within the last 10 years) mortality rates have increased at a slower rate or have decreased, particularly in men. ${ }^{22,34,35,42,43,45}$ Some remarkable differences in COPD mortality exist between countries, particularly regarding the differences between men and women. In Australia, one study ${ }^{34}$ reported a decrease in COPD mortality in men between 1979 and 1997, whereas an increase was seen in women over the same period. In France, COPD mortality has increased in women over time, whereas a decrease has been reported in men. ${ }^{35}$ Data from several US studies show more heterogeneity. Data from two studies showed a clear increase in COPD mortality in women and only a slight increase in men between 1980 and 2000. ${ }^{15,45}$ Data from a later study ${ }^{43}$ suggested that COPD mortality decreased between 2000 and 2005 in men, with little change in women.

\section{Discussion}

We conducted a structured and comprehensive literature review to identify published data on the prevalence, incidence, and mortality in COPD, and/or trends in those data. The review identified a wealth of data on the prevalence of COPD in the eleven countries studied (Australia, Canada, France, Germany, Italy, Japan, The Netherlands, Spain, Sweden, the UK, and the USA). However, data on mortality and incidence were sparser. Only 15 articles reported incidence data, and six reported trends in incidence; 21 articles reported mortality from COPD within the whole population, and 14 of those reported trends in those data.

Several other literature reviews have previously been conducted to identify prevalence and/or mortality data. ${ }^{50-53}$ One of these reported data only for the Asia-Pacific region and, of those countries investigated here, included only Japan..$^{53}$ Results from the other three literature reviews can be compared with findings from our review. One review included articles published between 1962 and 2001 that were indexed on MEDLINE, ${ }^{51}$ one review included articles published between 1990 and 2004 that were indexed on PubMed, and also provided pooled estimates of prevalence by means of a meta-analysis,${ }^{52}$ and the third review included articles reporting prevalence, and/or mortality in Europe published between 1991 and 2009 in the Science Citation Index database via the Web of Science. ${ }^{50}$

As with our study, all three published reviews reported substantial heterogeneity between studies, particularly in terms of the definition of COPD used, methods used (eg, selfreport, spirometry), diagnostic criteria (eg, GOLD, ATS), populations studied, and year(s) of study. ${ }^{50-53}$ The estimates obtained from the multicountry studies in our review ranged from $3.6 \%-10.1 \%$, which is in line with the estimates reported in two of the previous reviews $\left(4 \%-10 \%,{ }^{1} 19 \%-10 \%{ }^{52}\right)$. When all studies in our review were taken into account, prevalence estimates ranged from $0.2 \%-37 \%$, which was in line with the most recent published review $\left(2.1 \%-26.1 \%{ }^{50}\right)$. Differences can be accounted for by the wider scope of our study, which identified 80 studies reporting prevalence estimates in Europe, the USA, Canada, Australia, and Japan compared with 32 studies reporting estimates for Europe only, as identified by Atsou et al..$^{50}$

Our findings with respect to mortality were also similar to those reported in a recent literature review regarding both mortality within the overall population (3-111 per 100,000 [current review] versus 7.2-36.1 per 100,000 [review by Atsou et $\mathrm{al}^{50}$ ]) and the greater mortality rate in men compared with women..$^{50}$ The slightly higher mortality rates identified in our studies again relate to the scope of the two reviews. The lowest and highest mortality estimates in our review were from Japan and the USA, respectively, ${ }^{38,54}$ which were not captured in the European-focused literature review. ${ }^{50}$ Therefore, it is likely that the inclusion of countries outside Europe led to the greater heterogeneity in estimates that were identified in our review.

The current review also reported that, although COPD mortality rates have increased over time, rates have declined in more recent years, which suggests improvements in COPD management. However, several studies identified within the review also reported that the mortality rate in women with COPD has increased or stabilized, whereas it has decreased in men.

The difference in these trends may be explained by trends in smoking prevalence in the countries of interest. A relationship between smoking and COPD mortality can be investigated by examining trends in smoking prevalence such as using data from the Organisation for Economic Co-operation and Development (OECD). ${ }^{55}$ 


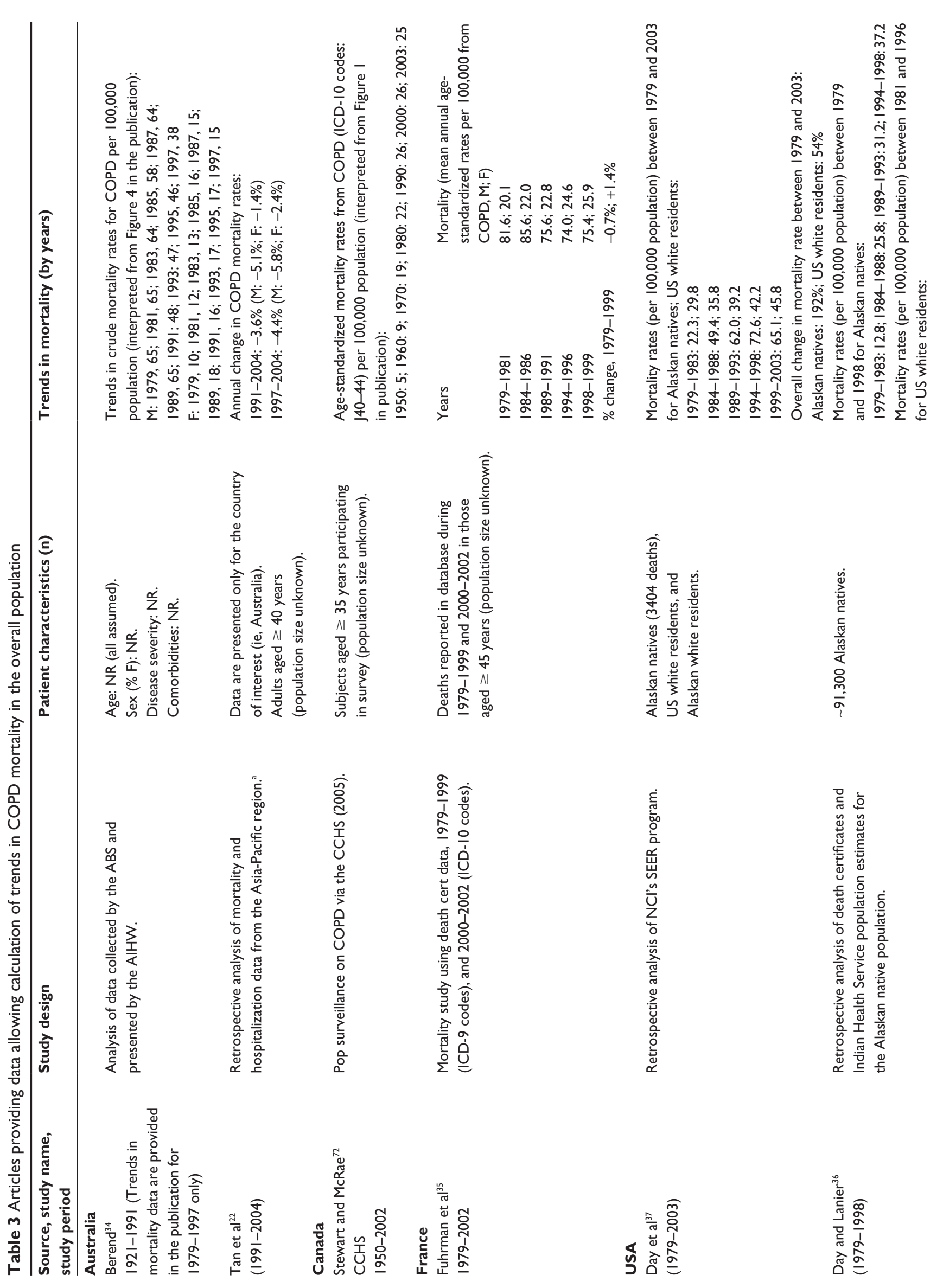



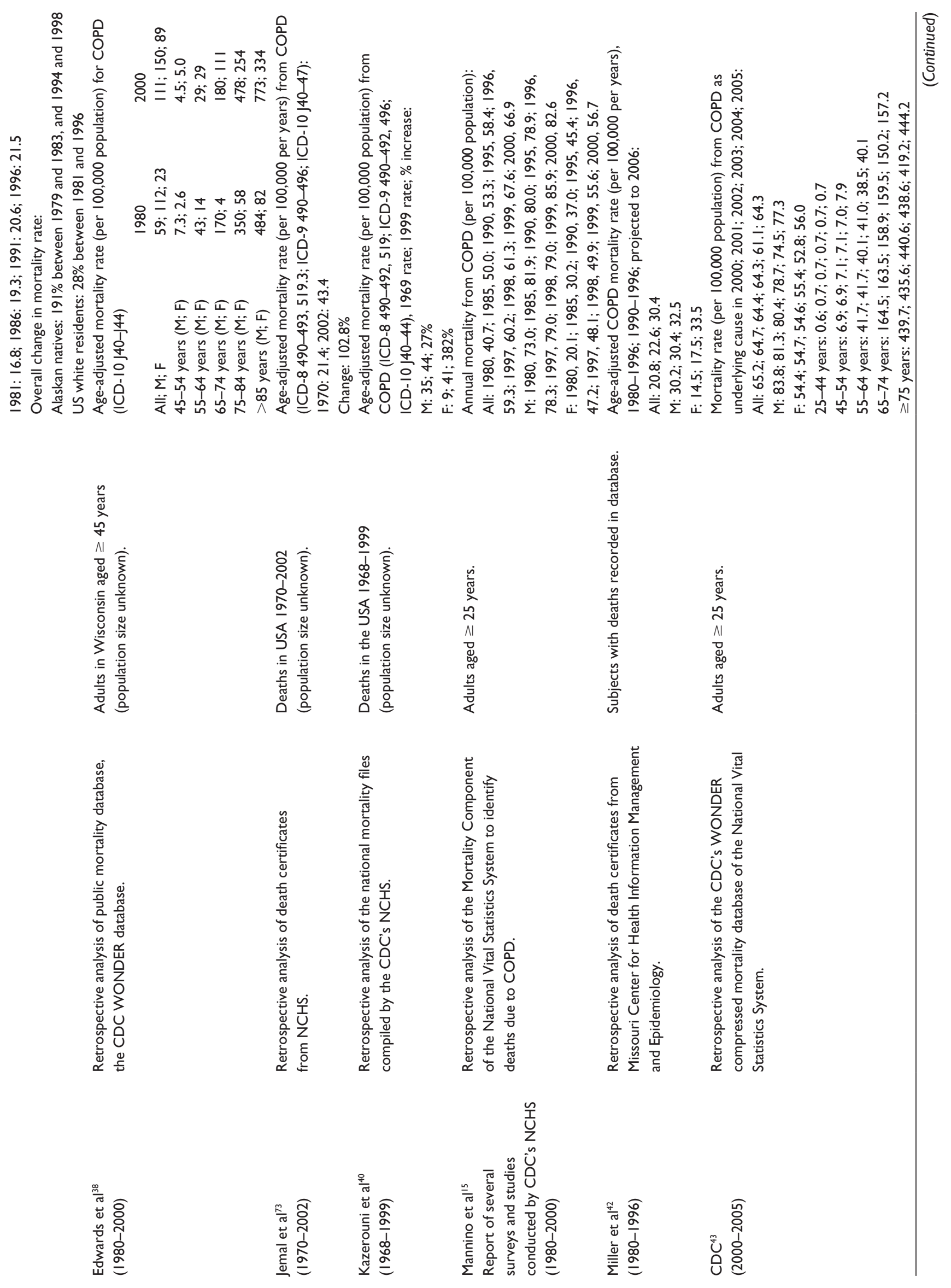


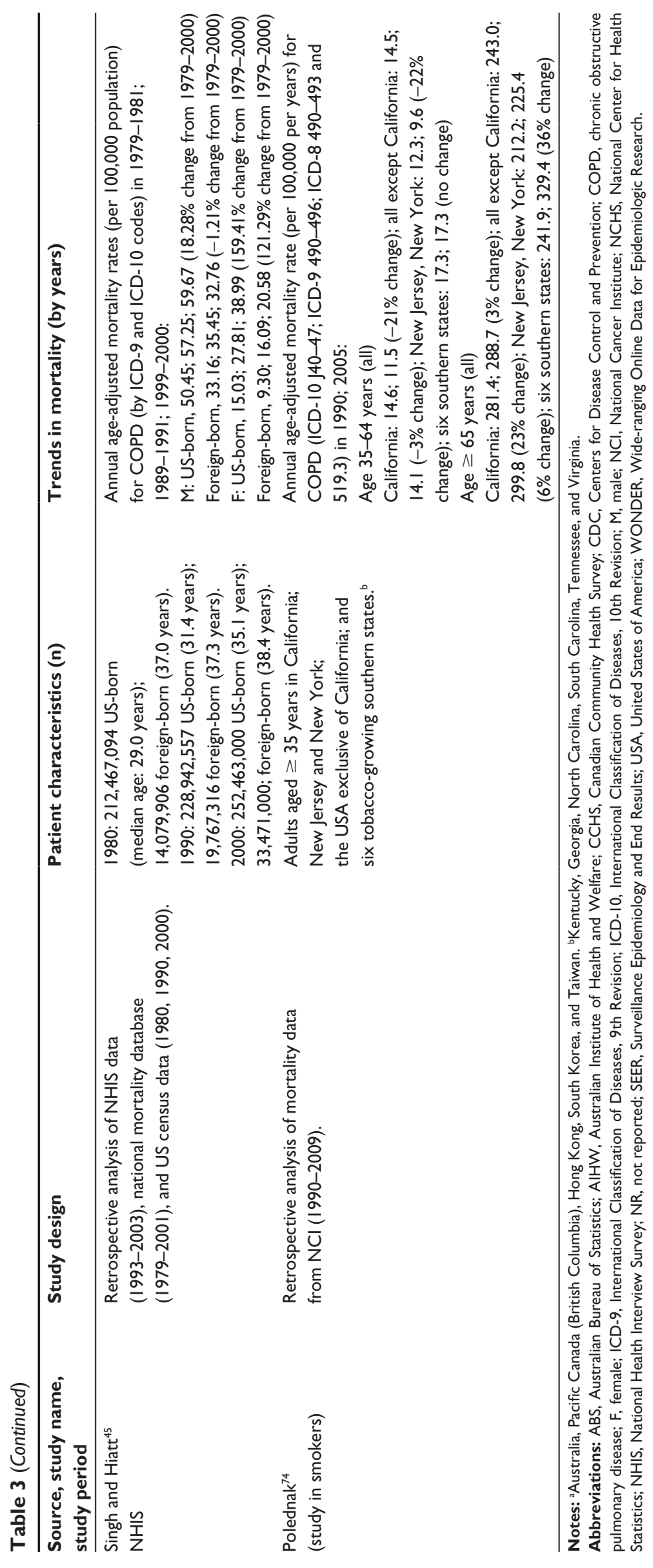


We were specifically interested in those countries where a difference in COPD mortality trends was observed between men and women (ie, Australia, France, and the USA). These countries all showed an overall decline in smoking rates with the greatest prevalence in men. ${ }^{55}$ Recently, the discrepancy in smoking rate between men and women has reduced because the rate in men has declined at a much greater rate than in women.

In Australia, ${ }^{34}$ COPD mortality between 1979 and 1997 followed a pattern similar to that observed in smoking prevalence between 1965 and 1980, with a decrease in men and an increase in women. The mortality data mirrored the smoking patterns with a delay of 15-20 years in women and 20-25 years in men. This "lag time" between smoking and COPD onset has been reported in previous literature. ${ }^{46}$ In France, both smoking prevalence and COPD mortality have increased over time, whereas a decrease in smoking prevalence and COPD mortality has been reported in men. ${ }^{35}$ Smoking prevalence data in France were not available from the OECD before 1981, which made it difficult to determine whether a lag time between smoking and COPD onset occurred. However, COPD mortality data from US studies show more heterogeneity; smoking prevalence substantially decreased over time in both men and women, whereas COPD mortality increased to a greater extent in women than men between 1980 and 2000, after which a decrease was observed in men, and a plateau in women between 2000 and 2005.

Although smoking prevalence might explain some of the discrepancy between men and women in COPD mortality, other reasons must be considered as well. Recent evidence suggests that women younger than 55 years are significantly more susceptible to severe COPD than men. ${ }^{56}$ Furthermore, women tend to have smaller airways and lung volumes than men, ${ }^{57}$ and previous studies have shown that females are consequently more vulnerable to the adverse effects of smoking than men. ${ }^{58-60}$

As with all literature reviews, both the current review and the data identified had certain limitations. First, this review focused on only eleven countries of interest (Australia, Canada, France, Germany, Italy, Japan, The Netherlands, Spain, Sweden, the UK, and the USA). Although the literature search itself was not restricted to certain countries, articles related only to countries outside those of interest were excluded from the review during the screening process. Second, the search was limited to articles published in English, so we may not have identified relevant articles published in other languages, particularly those relating to the non-English-speaking countries of interest. Third, several articles did not report true population-based estimates of prevalence or incidence, but instead reported prevalence or incidence of COPD within a population at increased risk for the condition. Fourth, and as with similar reviews involving searches of literature databases, any articles that were not indexed in PubMed or EMBASE would not have been initially identified. Fifth, the studies varied widely in the ages of populations studied, so they were difficult to compare and to draw conclusions from overall. Finally, differences between countries in terms of COPD diagnosis and management will also lead to discrepancies and hinder meaningful comparisons across countries.

However, our review has certain strengths when compared with other similar literature reviews in the epidemiology of COPD. Our review was a comprehensive literature review that identified literature from the MEDLINE and EMBASE databases. Furthermore, we investigated data on prevalence, incidence, and mortality as well as trends in prevalence, incidence, and mortality. Our review included more recent data (published from January 2000 to September 2010) compared with the previous reviews. ${ }^{51,52}$ Also, compared with the most recent review, which only reviewed data from countries in Europe, ${ }^{50}$ our review considered data from Australia, Canada, Japan, and the USA as well as from European countries. Consequently, we anticipate that our review contains more complete epidemiology data that present a current picture of the burden of COPD in major developed countries.

Although our review reported an overall decrease in the burden of COPD, in incidence, prevalence, and mortality in certain countries in recent years, ${ }^{18,22,25,26,31,61,62} \mathrm{COPD}$ remains a substantial health problem throughout the world. We found that several data gaps exist within the current literature on the epidemiology of COPD, particularly regarding studies reporting the incidence of COPD or trends in mortality data. Also, no studies were identified that reported incidence or trends in incidence in France, Germany, Italy, Spain, and The Netherlands, or trends in overall mortality in Germany, Italy, Japan, The Netherlands, Spain, Sweden, or the UK. A need exists for studies in these countries to examine trends in COPD incidence and mortality to fully understand the true burden of COPD in the population. There is also a need to continue to improve uniformity in definitions and methods of diagnosis to improve understanding of the burden of disease and aid in clearer evaluation of the patient response to treatment.

\section{Acknowledgments}

This study was sponsored by Boehringer Ingelheim $\mathrm{GmbH}$. Dr Rycroft, Ms Heyes, and Dr Lanza are full-time employees 
of RTI Health Solutions. Dr Becker is a full-time employee of Boehringer Ingelheim $\mathrm{GmbH}$.

\section{Disclosure}

The authors report no conflicts of interest in this work.

\section{References}

1. Rabe KF, Hurd S, Anzueto A, et al; Global Initiative for Chronich Obstructive Lung Disease. Global strategy for the diagnosis, management, and prevention of chronic obstructive pulmonary disease: GOLD executive summary. Am J Respir Crit Care Med. 2007;176(6): $532-555$.

2. Murray CJL, Lopez AD. Alternative projections of mortality and disability by cause 1990-2020: Global burden of disease study. Lancet. 1997;349:1498-1504.

3. Moher D, Liberati A, Tetzlaff J, Altman DG, PRISMA Group. Preferred reporting items for systematic reviews and meta-analyses: the PRISMA statement. Ann Intern Med. 2009;151(4):264-269, W64.

4. Lindberg A, Jonsson AC, Rönmark E, Lundgren R, Larsson LG, Lundbäck B. Prevalence of chronic obstructive pulmonary disease according to BTS, ERS, GOLD, and ATS criteria in relation to doctor's diagnosis, symptoms, age, gender, and smoking habits. Respiration. 2005;72(5):471-479.

5. Celli BR, Halbert RJ, Isonaka S, Schau B. Population impact of different definitions of airway obstruction. Eur Respir J. 2003;22(2): 268-273.

6. Hnizdo E, Glindmeyer HW, Petsonk EL, Enright P, Buist AS. Case definitions for chronic obstructive pulmonary disease. COPD. 2006; 3(2):95-100.

7. Vaz Fragoso CA, Concato J, McAvay G, et al. The ratio of FEV 1 to $\mathrm{FVC}$ as a basis for establishing chronic obstructive pulmonary disease. Am J Respir Crit Care Med. 2010;181(5):446-451.

8. Lindberg A, Bjerg A, Rönmark E, Larsson LG, Lundbäck B. Prevalence and underdiagnosis of COPD by disease severity and the attributable fraction of smoking. Report from the obstructive lung disease in Northern Sweden studies. Respir Med. 2006;100(2):264-272.

9. Lundbäck B, Lindberg A, Lindstrom M, et al; Obstructive Lung Disease in Northern Sweden Studies. Not 15 but $50 \%$ of smokers develop COPD? - Report from the Obstructive Lung Disease in Northern Sweden Studies. Respir Med. 2003;97(2):115-122.

10. Cerveri I, Accordini S, Verlato G, et al; European Community Respiratory Health Survey (ECRHS) Study Group. Variations in the prevalence across countries of chronic bronchitis and smoking habits in young adults. Eur Respir J. 2001;18(1):85-92.

11. Al-Hazmi M, Wooldrage K, Anthonisen NR, et al. Airflow obstruction in young adults in Canada. Can Respir J. 2007;14(4):221-217.

12. Viegi G, Matteelli G, Angino A, et al. The proportional Venn diagram of obstructive lung disease in the Italian general population. Chest. 2004;126(4): 1093-1101.

13. Celli BR, Halbert RJ, Nordyke RJ, Schau B. Airway obstruction in never smokers: results from the third national health and nutrition examination survey. Am J Med. 2005;118(12):1364-1372.

14. Hnizdo E, Sullivan PA, Bang KM, Wagner G. Association between chronic obstructive pulmonary disease and employment by industry and occupation in the US population: a study of data from the third national health and nutrition examination survey. Am J Epidemiol. 2002;156(8): 738-746.

15. Mannino DM, Homa DM, Akinbami LJ, Ford ES, Redd SC. Chronic obstructive pulmonary disease surveillance: United States, 1971-2000. MMWR Surveill Summ. 2002;51(6):1-16.

16. Methvin JN, Mannino DM, Casey BR. COPD prevalence in southeastern Kentucky: the burden of lung disease study. Chest. 2009;135(1): 102-107.
17. de Marco R, Accordini S, Cerveri I, et al. Incidence of chronic obstructive pulmonary disease in a cohort of young adults according to the presence of chronic cough and phlegm. Am J Respir Crit Care Med. 2007;175(1):32-39.

18. Gershon AS, Wang C, Wilton AS, Raut R, To T. Trends in chronic obstructive pulmonary disease prevalence, incidence, and mortality in Ontario, Canada, 1996 to 2007: a population-based study. Arch Intern Med. 2010;170(6):560-565.

19. Kojima S, Sakakibara H, Motani S, et al. Incidence of chronic obstructive pulmonary disease, and the relationship between age and smoking in a Japanese population. J Epidemiol. 2007;17(2): $54-60$.

20. Lindberg A, Jonsson AC, Rönmark E, Lundgren R, Larsson LG, Lundbäck B. Ten-year cumulative incidence of COPD and risk factors for incident disease in a symptomatic cohort. Chest. 2005;127(5): $1544-1552$.

21. García Rodríguez LA, Wallander MA, Tolosa LB, Johansson S. Chronic obstructive pulmonary disease in UK primary care: incidence and risk factors. COPD. 2009;6(5):369-379.

22. Tan WC, Seale P, Ip M, et al. Trends in COPD mortality and hospitalizations in countries and regions of Asia-Pacific. Respirology. 2009;14(1):90-97.

23. Lindgren B. Trends in obstructive lung disease in hospital registers in Sweden 1987-1996. Eur Respir Rev. 2000;10(75):423.

24. Lipton R, Banerjee A. The geography of chronic obstructive pulmonary disease across time: California in 1993 and 1999. Int J Med Sci. 2007; 4(4):179-189.

25. Kabir Z, Connolly GN, Koh HK, Clancy L. Chronic obstructive pulmonary disease hospitalization rates in Massachusetts: a trend analysis. QJM. 2010;103(3):163-168.

26. Lindberg A, Eriksson B, Larsson LG, Rönmark E, Sandstrom T, Lundbäck B. Seven-year cumulative incidence of COPD in an agestratified general population sample. Chest. 2006;129(4):879-885.

27. Camp PG, Chaudhry M, Platt H, et al. The sex factor: epidemiology and management of chronic obstructive pulmonary disease in British Columbia. Can Respir J. 2008;15(8):417-422.

28. Nie JX, Wang L, Upshur RE. Mortality of elderly patients in Ontario after hospital admission for chronic obstructive pulmonary disease. Can Respir J. 2007;14(8):485-489.

29. Lindberg A, Lundbäck B. The Obstructive Lung Disease in Northern Sweden Chronic Obstructive Pulmonary Disease Study: design, the first year participation and mortality. Clin Respir J. 2008;2(Suppl 1): 64-71.

30. Janssen F, Kunst AE. Cohort patterns in mortality trends among the elderly in seven European countries, 1950-1999. Int J Epidemiol. 2005; 34(5):1149-1159.

31. Wilson DH, Tucker G, Frith P, Appleton S, Ruffin RE, Adams RJ. Trends in hospital admissions and mortality from asthma and chronic obstructive pulmonary disease in Australia, 1993-2003. Med J Aust. 2007;186(8):408-411.

32. Janssen F, Nusselder WJ, Looman CW, Mackenbach JP, Kunst AE. Stagnation in mortality decline among elders in The Netherlands. Gerontologist. 2003;43(5):722-734.

33. Hansell AL, Walk JA, Soriano JB. What do chronic obstructive pulmonary disease patients die from? A multiple cause coding analysis. Eur Respir J. 2003;22(5):809-814.

34. Berend N. Epidemiological survey of chronic obstructive pulmonary disease and alpha-1-antitrypsin deficiency in Australia. Respirology. 2001;(Suppl 6):S21-S25.

35. Fuhrman C, Jougla E, Nicolau J, Eilstein D, Delmas MC. Deaths from chronic obstructive pulmonary disease in France, 1979-2002: a multiple cause analysis. Thorax. 2006;61(11):930-934.

36. Day GE, Lanier AP. Alaska native mortality, 1979-1998. Public Health Rep. 2003;118(6):518-530.

37. Day GE, Provost E, Lanier AP. Alaska native mortality rates and trends. Public Health Rep. 2009;124(1):54-64. 
38. Edwards NM, Umland M, Ahrens D, Remington P. The silent epidemic among Wisconsin women: chronic obstructive pulmonary disease trends, 1980-2000. WMJ. 2005;104(4):50-54.

39. Hughes TS, Muldoon SB, Tollerud DJ. Underestimation of mortality due to chronic obstructive pulmonary disease (COPD) in Kentucky. J Ky Med Assoc. 2006;104(8):331-339.

40. Kazerouni N, Alverson CJ, Redd SC, Mott JA, Mannino DM. Sex differences in COPD and lung cancer mortality trends: United States, 1968-1999. J Womens Health. (Larchmt). 2004;13(1):17-23.

41. Lewis DR, Clegg LX, Johnson NJ. Lung disease mortality in the United States: the national longitudinal mortality study. Int J Tuberc Lung Dis. 2009;13(8):1008-1014.

42. Miller N, Simoes EJ, Chang JC, Robling AG. Trends in chronic obstructive pulmonary disease mortality. Mo Med. 2000;97(3):87-90.

43. Centers for Disease Control and Prevention (CDC). Deaths from chronic obstructive pulmonary disease: United States, 2000-2005. MMWR Morb Mortal Wkly Rep. 2008;57(45):1229-1232.

44. Rubia M, Marcos I, Muennig PA. Increased risk of heart disease and stroke among foreign-born females residing in the United States. Am J Prev Med. 2002;22(1):30-35.

45. Singh GK, Hiatt RA. Trends and disparities in socioeconomic and behavioural characteristics, life expectancy, and cause-specific mortality of native-born and foreign-born populations in the United States, 1979-2003. Int J Epidemiol. 2006;35(4):903-919.

46. Ezzati M, Lopez AD. Regional, disease specific patterns of smokingattributable mortality in 2000. Tob Control. 2004;13(4):388-395.

47. Centers for Disease Control and Prevention (CDC). Smoking-attributable mortality, years of potential life lost, and productivity losses: United States, 2000-2004. MMWR Morb Mortal Wkly Rep. 2008;57(45): 1226-1228.

48. Ezzati M, Lopez AD. Estimates of global mortality attributable to smoking in 2000. Lancet. 2003;362(9387):847-852.

49. Henley SJ, Connell CJ, Richter P, et al. Tobacco-related disease mortality among men who switched from cigarettes to spit tobacco. Tob Control. 2007;16(1):22-28.

50. Atsou K, Chouaid C, Hejblum G. Variability of the chronic obstructive pulmonary disease key epidemiological data in Europe: systematic review. BMC Med. 2011;9:7.

51. Halbert RJ, Isonaka S, George D, Iqbal A. Interpreting COPD prevalence estimates: what is the true burden of disease? Chest. 2003; 123(5):1684-1692.

52. Halbert RJ, Natoli JL, Gano A, Badamgarav E, Buist AS, Mannino DM. Global burden of COPD: systematic review and meta-analysis. Eur Respir J. 2006;28(3):523-532.

53. Ko FW, Hui DS, Lai CK. Worldwide burden of COPD in high- and low-income countries, Part III. Asia-Pacific studies. Int J Tuberc Lung Dis. 2008;12(7):713-717.

54. Hurd S. The impact of COPD on lung health worldwide: epidemiology and incidence. Chest. 2000;117(Suppl 2):1S-4S.

55. OECD.StatExtracts [homepage on the Internet]. Organisation for Economic Co-operation and Development; 2011. Non-medical determinants of health: tobacco consumption. Available from: http:// stats.oecd.org/index.aspx. Accessed July 13, 2011.

56. Foreman MG, Zhang L, Murphy J, et al. The COPDGene investigators. Early-onset COPD is associated with female gender, maternal factors, and African-American race in the COPDGene study. Am J Respir Crit Care Med. 2011;184(4):414-420.

57. Sheel AW, Guenette JA. Mechanics of breathing during exercise in men and women: sex versus body size differences? Exerc Sport Sci Rev. 2008;36(3):128-134.

58. Prescott E, Bjerg AM, Andersen PK, Lange P, Vestbo J. Gender difference in smoking effects on lung function and risk of hospitalization for COPD: results from a Danish longitudinal population study. Eur Respir J. 1997;10(4):822-827.

59. Langhammer A, Johnsen R, Gulsvik A, Holmen TL, Bjermer L. Sex differences in lung vulnerability to tobacco smoking. Eur Respir J. 2003;21(6):1017-1823.
60. Guenette JA, Jensen D, Webb KA, Ofir D, Raghavan N, O’Donnell DE Sex differences in exertional dyspnea in patients with mild COPD: physiological mechanisms. Respir Physiol Neurobiol. 2011;177(3): 218-227.

61. Thomas DP, Condon JR, Anderson IP, et al. Long-term trends in indigenous deaths from chronic diseases in the Northern Territory: a foot on the brake, a foot on the accelerator. Med J Aust. 2006;185(3): 145-149.

62. Bischoff EW, Schermer TR, Bor H, Brown P, van Weel C, van den Bosch WJ. Trends in COPD prevalence and exacerbation rates in Dutch primary care. Br J Gen Pract. 2009;59(569):927-933.

63. Cricelli C, Mazzaglia G, Samani F, et al. Prevalence estimates for chronic diseases in Italy: exploring the differences between self-report and primary care databases. J Public Health Med. 2003;25(3):254-257.

64. Montnémery R, Nihlen U, Andersson M, et al. Obstructive airways diseases, smoking, and use of inhaled corticosteroids in southern Sweden in 1992 and 2000. Int J Tuberc Lung Dis. 2006;10(5):490-498.

65. Shahab L, Jarvis MJ, Britton J, West R. Prevalence, diagnosis, and relation to tobacco dependence of chronic obstructive pulmonary disease in a nationally representative population sample. Thorax. 2006;61(12): 1043-1047.

66. Soriano JB, Davis KJ, Coleman B, Visick G, Mannino D, Pride NB. The proportional Venn diagram of obstructive lung disease: two approximations from the United States and the United Kingdom. Chest. 2003;124(2):474-481.

67. Mannino DM, Gagnon RC, Petty TL, Lydick E. Obstructive lung disease and low lung function in adults in the United States: data from the national health and nutrition examination survey, 1988-1994. Arch Intern Med. 2000;160(11):1683-1689.

68. American Thoracic Society. Evaluation of impairment/disability secondary to respiratory disorders. Am Rev Respir Dis. 1986;133: 1205-1209.

69. Siafakas NM, Vermeire P, Pride NB, et al. Optimal assessment and management of chronic obstructive pulmonary disease (COPD). The European Respiratory Society Task Force. Eur Respir J. Aug 1995;8(8): 1398-1420.

70. Nihlen U, Nyberg P, Montnémery P, Lofdahl CG. Influence of family history and smoking habits on the incidence of self-reported physician's diagnosis of COPD. Respir Med. 2004;98(3):263-270.

71. Soriano JB, Maier WC, Egger P, et al. Recent trends in physician diagnosed COPD in women and men in the UK. Thorax. 2000;55(9): 789-794.

72. Stewart P, McRae L. Keeping track of COPD in Canada. Can Respir J. 2007;14(Suppl A):5A-7A.

73. Jemal A, Ward E, Hao Y, Thun M. Trends in the leading causes of death in the United States, 1970-2002. JAMA. 2005;294(10):1255-1259.

74. Polednak AP. Trends in mortality from COPD in selected US states differing in tobacco control efforts. COPD. 2010;7(1):63-69.

75. Boutin-Forzano S, Moreau D, Kalaboka S, et al. Reported prevalence and co-morbidity of asthma, chronic bronchitis and emphysema: A panEuropean estimation. Int J Tuberc Lung Dis. 2007;11(6):695-702.

76. Buist AS, McBurnie MA, Vollmer WM, et al. International variation in the prevalence of COPD (the BOLD Study): a population-based prevalence study. Lancet. 2007;370(9589):741-750.

77. Menotti A, Mulder I, Nissinen A, Giampaoli S, Feskens EJ, Kromhout D. Prevalence of morbidity and multimorbidity in elderly male populations and their impact on 10-year all-cause mortality: The FINE study (Finland, Italy, Netherlands, Elderly). J Clin Epidemiol. 2001;54(7):680-686.

78. Rennard S, Decramer M, Calverley PM, et al. Impact of COPD in North America and Europe in 2000: subjects' perspective of Confronting COPD International Survey. Eur Respir J. 2002;20(4): 799-805.

79. Svanes C, Omenaas E, Jarvis D, Chinn S, Gulsvik A, Burney P. Parental smoking in childhood and adult obstructive lung disease: Results from the European Community Respiratory Health Survey. Thorax. 2004;59(4):295-302. 
80. de Marco R, Accordini S, Cerveri I, et al; European Community Respiratory Health Survey Study Group. An international survey of chronic obstructive pulmonary disease in young adults according to GOLD stages. Thorax. 2004;59(2):120-125.

81. Lacasse Y, Montori VM, Lanthier C, Maltis F. The validity of diagnosing chronic obstructive pulmonary disease from a large administrative database. Can Respir J. 2005;12(5):251-256.

82. Ohinmaa A, Schopflocher D, Jacobs P, et al. A population-based analysis of health behaviours, chronic diseases and associated costs. Chronic Dis Can. 2006;27(1):17-24.

83. Stewart P, McRae L. Keeping track of COPD in Canada. Can Respir J. 2007;14(Suppl A):5A-7A.

84. Chen Y, Breithaupt K, Muhajarine N. Occurrence of chronic obstructive pulmonary disease among Canadians and sex-related risk factors. J Clin Epidemiol. 2000;53(7):755-761.

85. Hill K, Goldstein RS, Guyatt GH, et al. Prevalence and underdiagnosis of chronic obstructive pulmonary disease among patients at risk in primary care. CMAJ. 2010;182(7):673-678.

86. Vozoris N, Lougheed MD. Second-hand smoke exposure in Canada: prevalence, risk factors, and association with respiratory and cardiovascular diseases. Can Respir J. 2008;15(5):263-269.

87. Huchon GJ, Vergnenegre A, Neukirch F, Brami G, Roche N, Preux PM. Chronic bronchitis among French adults: high prevalence and underdiagnosis. Eur Respir J. 2002;20(4):806-812.

88. Anecchino C, Rossi E, Fanizza C, De Rossi M, Tognoni G, Romero $\mathrm{M}$; working group ARNO project. Prevalence of chronic obstructive pulmonary disease and pattern of comorbidities in a general population. Int J Chron Obstruct Pulmon Dis. 2007;2(4):567-574.

89. Fukahori S, Matsuse H, Takamura N, et al. Prevalence of chronic obstructive pulmonary diseases in general clinics in terms of FEV1/ FVC. Int J Clin Pract. 2009;63(2):269-274.

90. Fukuchi Y, Nishimura M, Ichinose M, et al. COPD in Japan: the Nippon COPD Epidemiology study. Respirology. 2004;9(4):458-465.

91. Kojima S, Sakakibara H, Motani S, et al. Effects of smoking and age on chronic obstructive pulmonary disease in Japan. J Epidemiol. 2005;15(4):113-117.

92. Tatsumi K. Epidemiological survey of chronic obstructive pulmonary disease in Japan. Respirology. 2001;(6 Suppl):S27-S33.

93. Miravitlles M, de la Roza C, Morera J, et al. Chronic respiratory symptoms, spirometry and knowledge of COPD among general population. Respir Med. 2006;100(11):1973-1980.

94. Miravitlles M, Soriano JB, García-Río F, et al. Prevalence of COPD in Spain: impact of undiagnosed COPD on quality of life and daily life activities. Thorax. 2009;64(10):863-868.

95. Peña VS, Miravitlles M, Gabriel R, et al. Geographic variations in prevalence and underdiagnosis of COPD: results of the IBERPOC multicentre epidemiological study. Chest. 2000;118(4): 981-989.

96. de Torres JP, Campo A, Casanova C, Aguirre-Jaime A, Zulueta J. Gender and chronic obstructive pulmonary disease in high-risk smokers. Respiration. 2006;73(3):306-310.

97. Ekberg-Aronsson M, Lofdahl K, Nilsson JA, Lofdahl CG, Nilsson PM. Hospital admission rates among men and women with symptoms of chronic bronchitis and airflow limitation corresponding to the GOLD stages of chronic obstructive pulmonary disease--a population-based study. Respir Med. 2008;102(1):109-120.

98. Hasselgren M, Arne M, Lindahl A, Janson S, Lundbäck B. Estimated prevalences of respiratory symptoms, asthma and chronic obstructive pulmonary disease related to detection rate in primary health care. Scand J Prim Health Care. 2001;19(1):54-57.

99. Lindstrom M, Jonsson E, Larsson K, Lundbäck B. Underdiagnosis of chronic obstructive pulmonary disease in Northern Sweden. Int J Tuberc Lung Dis. 2002;6(1):76-84.

100. Montnémery P, Bengtsson P, Elliot A, Lindholm LH, Nyberg P, Lofdahl CG. Prevalence of obstructive lung diseases and respiratory symptoms in relation to living environment and socio-economic group. Respir Med. 2001;95(9):744-752.
101. Pallasaho P, Lundbäck B, Meren M, et al. Prevalence and risk factors for asthma and chronic bronchitis in the capitals Helsinki, Stockholm, and Tallinn. Respir Med. 2002;96(10):759-769.

102. Rönmark EP, Ekerljung L, Lötvall J, Torén K, Rönmark E, Lundbäck B. Large scale questionnaire survey on respiratory health in Sweden: Effects of late- and non-response. Respir Med. 2009;103(12):1807-1815.

103. Wiréhen AB, Karlsson HM, Carstensen JM. Estimating disease prevalence using a population-based administrative healthcare database. Scand J Public Health. 2007;35(4):424-431.

104. Faulconer ER, de Lusignan S. An eight-step method for assessing diagnostic data quality in practice: chronic obstructive pulmonary disease as an exemplar. Inform Prim Care. 2004;12(4):243-254.

105. Murtagh E, Heaney L, Gingles J, et al. Prevalence of obstructive lung disease in a general population sample: the NICECOPD study. Eur J Epidemiol. 2005;20(5):443-453.

106. Nacul LC, Soljak M, Meade T. Model for estimating the population prevalence of chronic obstructive pulmonary disease: Cross sectional data from the health survey for England. Popul Health Metr. 2007;5:8.

107. Bang KM, Syamlal G, Mazurek JM. Prevalence of chronic obstructive pulmonary disease in the U.S. working population: an analysis of data from the 1997-2004 National Health Interview Survey. COPD. 2009;6(5):380-387.

108. Bhattacharyya N. Contemporary assessment of the disease burden of sinusitis. Am J Rhinol Allergy. 2009;23(4):392-395.

109. Bhattacharyya N. Does annual temperature influence the prevalence of otolaryngologic respiratory diseases? Laryngoscope. 2009;119(10):1882-1886.

110. Chamberlain AM, Schabath MB, Folsom AR. Associations of chronic obstructive pulmonary disease with all-cause mortality in Blacks and Whites: the atherosclerosis risk in communities (ARIC) study. Ethn Dis. 2009;19(3):308-314.

111. Hnizdo E, Sullivan PA, Bang KM, Wagner G. Airflow obstruction attributable to work in industry and occupation among U.S. race/ethnic groups: a study of NHANES III data. Am J Ind Med. 2004;46(2):126-135.

112. Jackson H, Hubbard R. Detecting chronic obstructive pulmonary disease using peak flow rate: Cross sectional survey. $\mathrm{Br}$ Med $\mathrm{J}$. 2003;327(7416):653-654.

113. Jordan JG Jr, Mann JR. Obesity and mortality in persons with obstructive lung disease using data from the NHANES III. South Med J. 2010;103(4):323-330.

114. Lipton R, Banerjee A, Dowling KC, Treno AJ. The geography of COPD hospitalization in California. COPD. 2005;2(4):435-444.

115. Mannino DM, Buist AS, Petty TL, Enright PL, Redd SC. Lung function and mortality in the United States: data from the First National Health and Nutrition Examination Survey follow up study. Thorax. 2003;58(5):388-393.

116. O'Malley AS, Pham HH, Schrag D, Wu B, Bach PB. Potentially avoidable hospitalizations for COPD and pneumonia: the role of physician and practice characteristics. Med Care. 2007;45(6):562-570.

117. Pleis JR, Barnes PM. A comparison of respiratory conditions between multiple race adults and their single race counterparts: An analysis based on American Indian/Alaska Native and white adults. Ethn Health. 2008;13(5):399-415.

118. Schneider KM, O’Donnell BE, Dean D. Prevalence of multiple chronic conditions in the United States' Medicare population. Health Qual Life Outcomes. 2009;7:82.

119. Tinkelman DG, George D, Halbert RJ. Chronic obstructive pulmonary disease in patients under age 65: Utilization and costs from a managed care sample. J Occup Environ Med. 2005;47(11):1125-1130.

120. Wilson L, Devine EB, So K. Direct medical costs of chronic obstructive pulmonary disease: chronic bronchitis and emphysema. Respir Med. 2000;94(3):204-213.

121. Ohar JA, Sadeghnejad A, Meyers DA, Donohue JF, Bleecker ER. Do symptoms predict COPD in smokers? Chest. 2010;137(6):1345-1353. 


\section{Supplementary materials}

Table SI Search strategy used for literature search

\begin{tabular}{|c|c|}
\hline Search number & Search terms ${ }^{a}$ \\
\hline \multicolumn{2}{|l|}{ COPD } \\
\hline \multirow[t]{4}{*}{ \#I } & "Pulmonary Disease, Chronic Obstructive" [MeSH] OR "chronic obstructive \\
\hline & pulmonary disease"[Text Word] OR “COPD"[Text Word] OR "Pulmonary \\
\hline & Emphysema” [MeSH] OR “emphysema”[Text Word] OR "Bronchitis, \\
\hline & Chronic”[MeSH] OR “chronic bronchitis”[Text Word] \\
\hline \multicolumn{2}{|c|}{ Epidemiology data } \\
\hline \multirow[t]{3}{*}{$\# 2$} & "Epidemiology" $[\mathrm{MeSH}]$ OR “Incidence" [MeSH] OR "Prevalence" [MeSH] OR \\
\hline & "Cause of Death"[MeSH] OR ("Hospital Mortality" [MeSH] NOT “Hospital \\
\hline & Mortality/ethnology”[MeSH]) OR “Morbidity”[MeSH] \\
\hline \multirow[t]{7}{*}{ \#3 } & "Pulmonary Disease, Chronic Obstructive/epidemiology"[Majr] OR \\
\hline & "Pulmonary Disease, Chronic Obstructive/mortality”[Majr] OR \\
\hline & "Pulmonary Emphysema/epidemiology"[Majr] OR "Pulmonary Emphysema/ \\
\hline & mortality"[Majr] OR "Bronchitis, Chronic/epidemiology"[Majr] OR \\
\hline & “Bronchitis, Chronic/mortality”[Majr] OR “Lung Diseases, Obstructive/ \\
\hline & epidemiology”[Majr:NoExp] OR “Lung Diseases, Obstructive/ \\
\hline & mortality"[Majr:NoExp] \\
\hline \#4 & (\#I AND \#2) OR \#3 \\
\hline \multicolumn{2}{|c|}{ Exclusionary terms } \\
\hline \multirow[t]{4}{*}{$\# 5$} & "Comment"[Publication Type] OR “Editorial” \\
\hline & [Publication Type] OR “Letter”[Publication Type] OR “Case \\
\hline & Reports"[Publication Type] OR \\
\hline & “Clinical Trial”[Publication Type] \\
\hline \#6 & “Animals”[MeSH] NOT “Humans”[MeSH] $]^{b}$ \\
\hline \multicolumn{2}{|l|}{ Total } \\
\hline$\# 7$ & \#4 NOT (\#5 OR \#6) \\
\hline
\end{tabular}

Notes: aSearch limits: English language; and publication date from January 2000 to September 2010. "NOT ("Animals"[MeSH] NOT "Humans"[MeSH]) excludes articles that have only the tag for animal studies. By using this approach instead of selecting the "humans" limitation in PubMed, recent articles that have not been fully indexed (including the "humans" tag) but that are exclusively in humans will not be excluded.

Abbreviations: COPD, chronic obstructive pulmonary disease; MeSH, Medical Subject Headings.

Table S2 Summary of articles included in literature review

\begin{tabular}{|c|c|c|c|c|c|}
\hline \multirow[t]{2}{*}{ Country } & \multicolumn{5}{|c|}{ Number of articles reporting data types ${ }^{a}$} \\
\hline & All articles & Multicountry articles & Prevalence & Incidence & Mortality \\
\hline Multicountry studies & 19 & NA & 12 & 2 & 7 \\
\hline Australia & 4 & 4 & 2 & I & 6 \\
\hline Canada & 12 & 4 & 13 & 2 & 6 \\
\hline France & 2 & 4 & 3 & 0 & 3 \\
\hline Germany & 1 & 4 & 4 & 0 & 1 \\
\hline Italy & 3 & 5 & 7 & 0 & 2 \\
\hline Japan & 6 & 2 & 5 & I & 2 \\
\hline The Netherlands & 2 & 5 & 4 & 0 & 4 \\
\hline Spain & 7 & 5 & 7 & 0 & 5 \\
\hline Sweden & 19 & 4 & 14 & 4 & 7 \\
\hline The United Kingdom & 9 & 5 & II & 2 & 4 \\
\hline The United States & 49 & 6 & 29 & 4 & 30 \\
\hline Total & 133 & NA & 80 & 15 & 58 \\
\hline
\end{tabular}

Notes: ${ }^{\text {AAll }}$ numbers reported in this table also include any multicountry studies that also provided separate data in the countries of interest. Therefore, a multicountry article could be counted more than once in each column.

Abbreviation: NA, not applicable. 


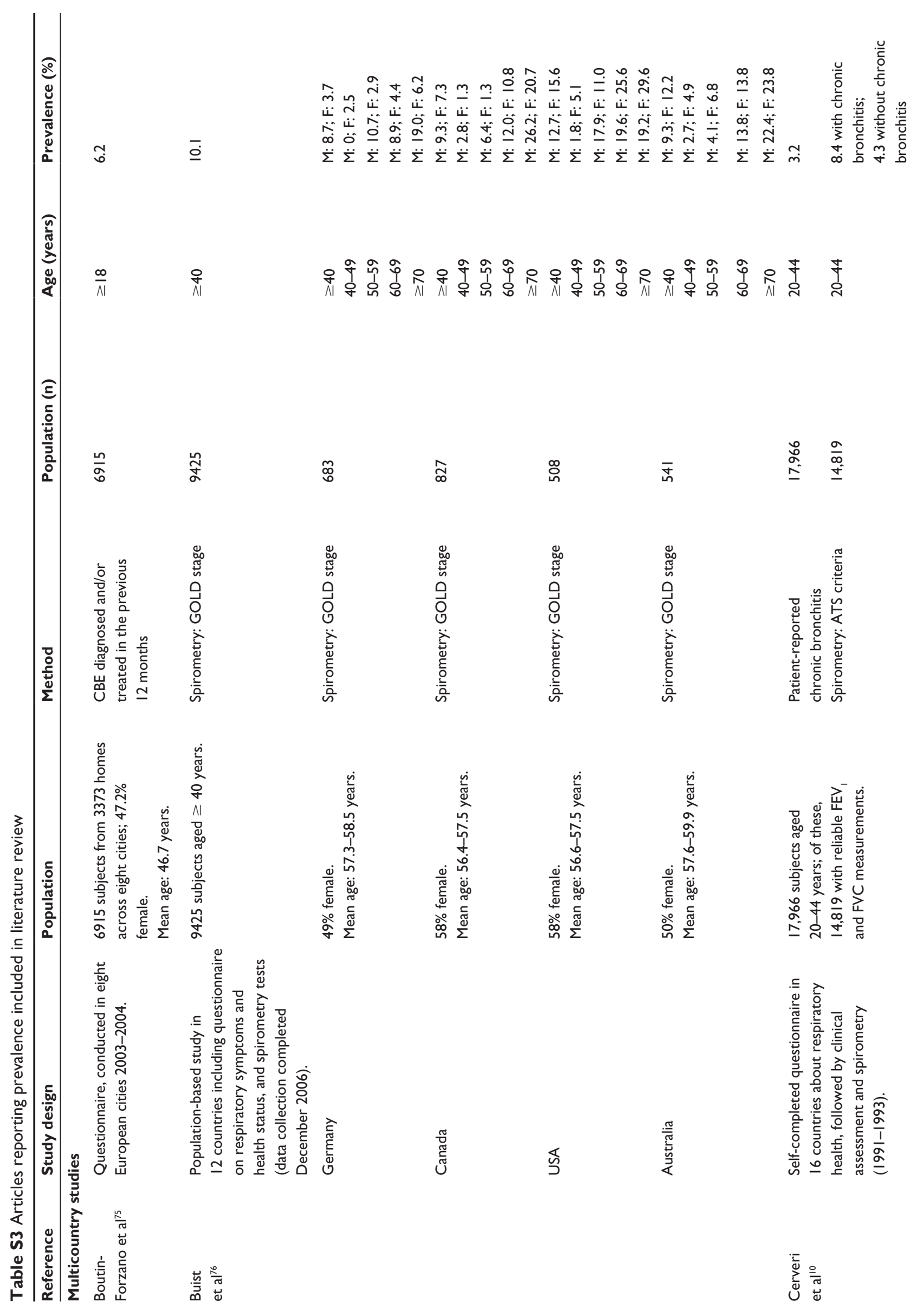




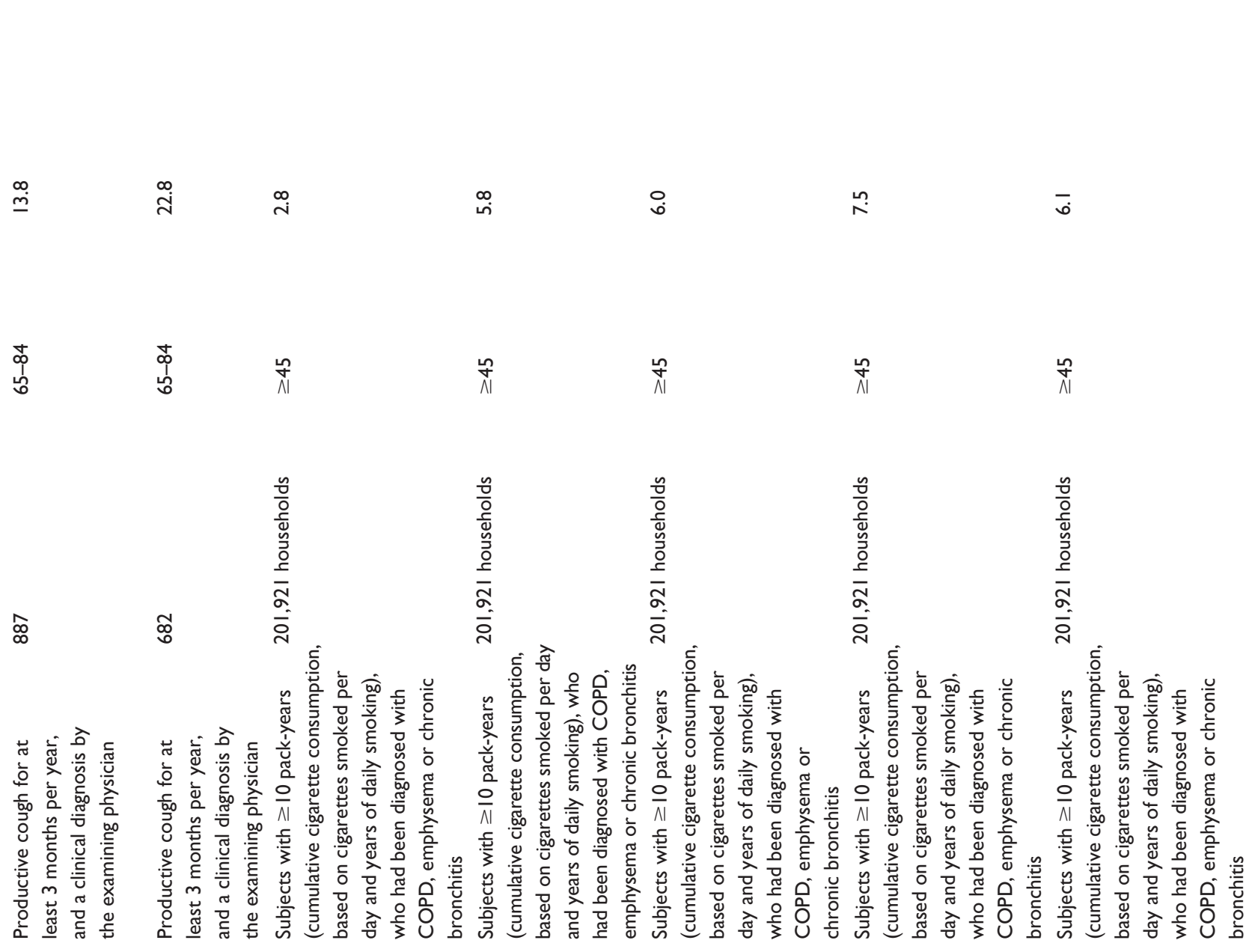

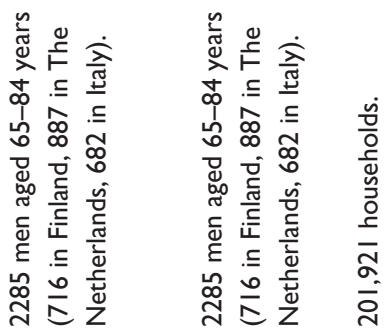
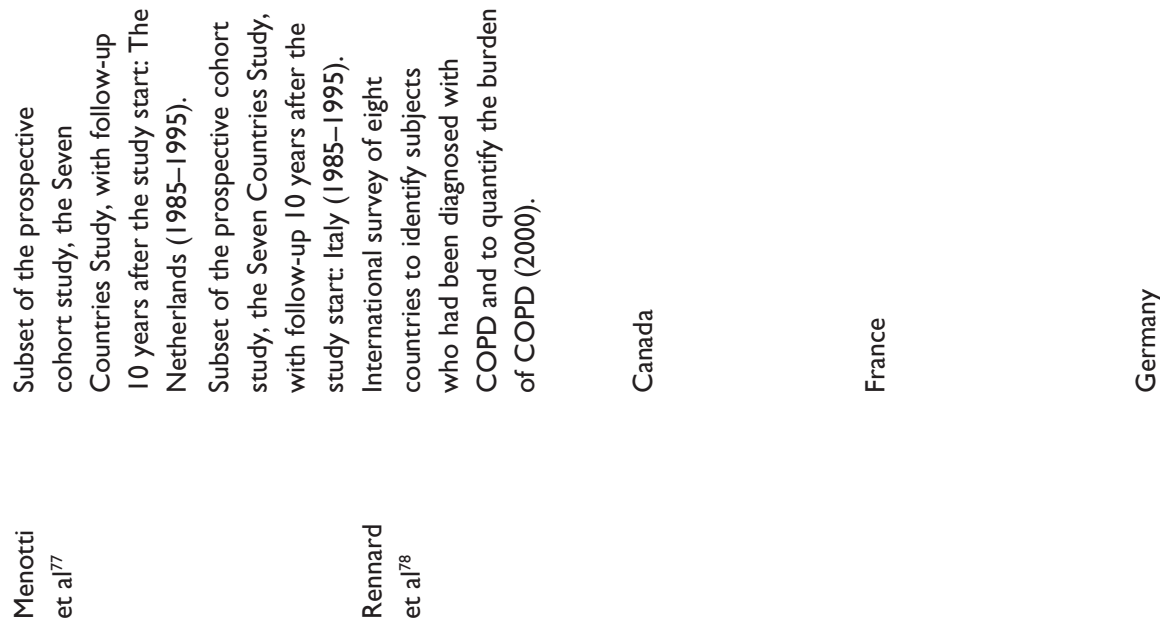


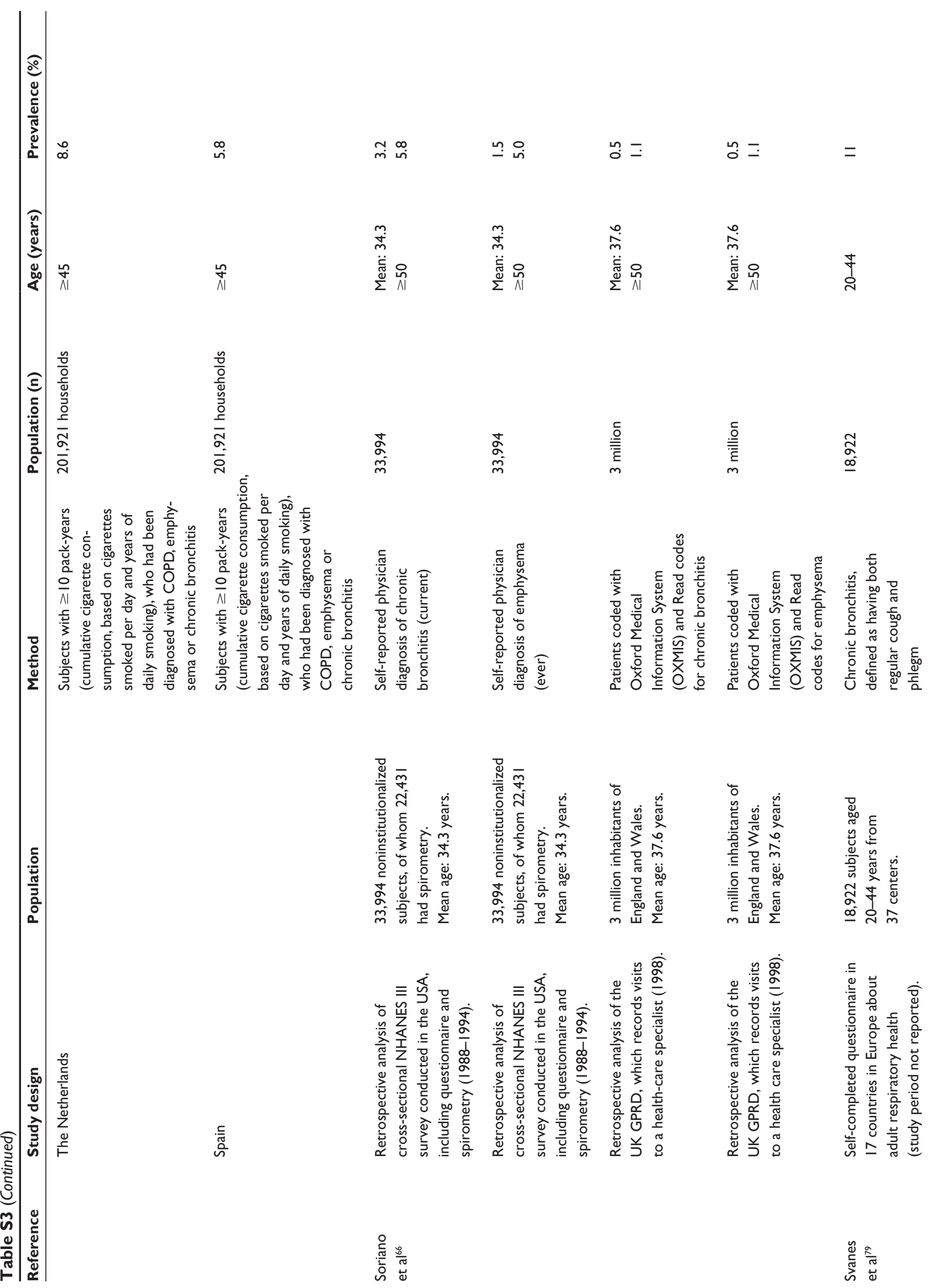




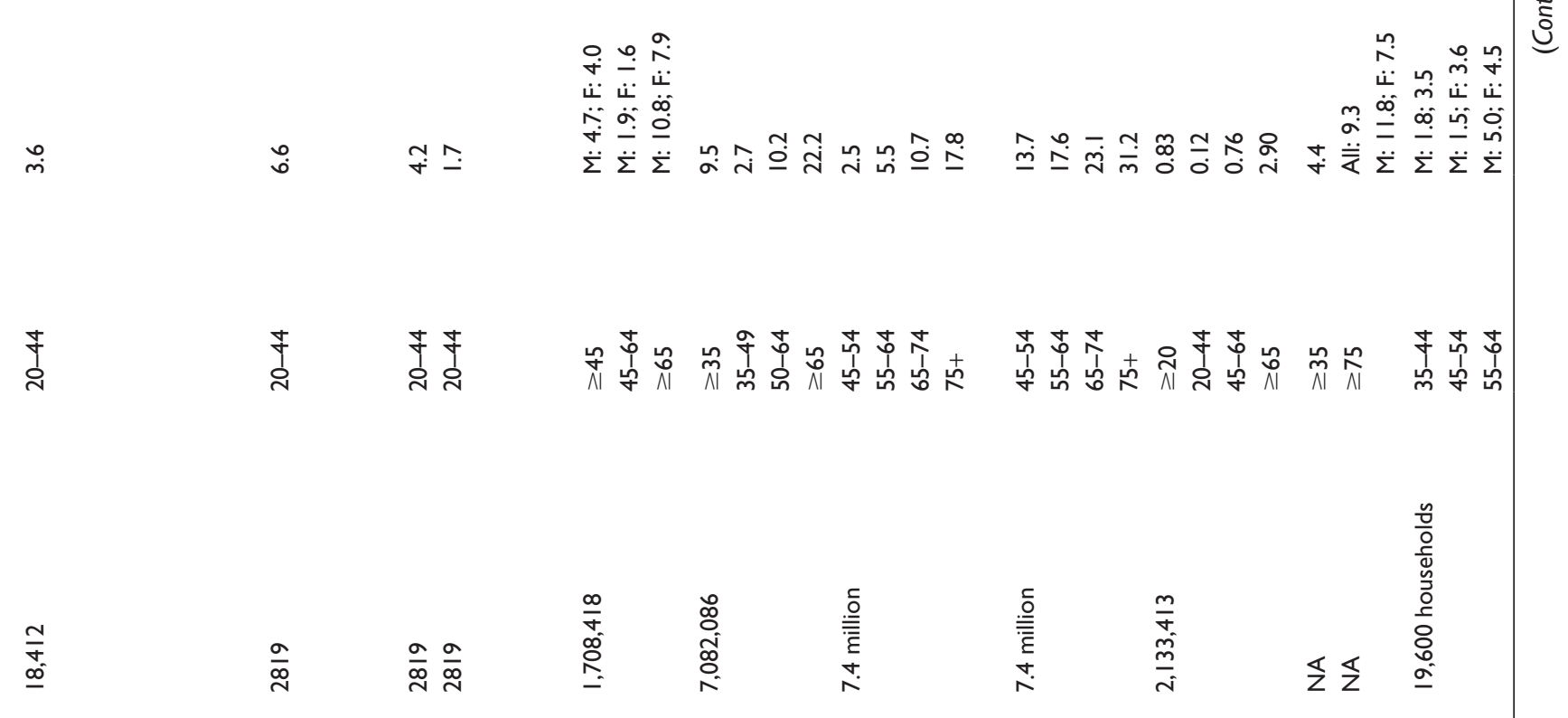

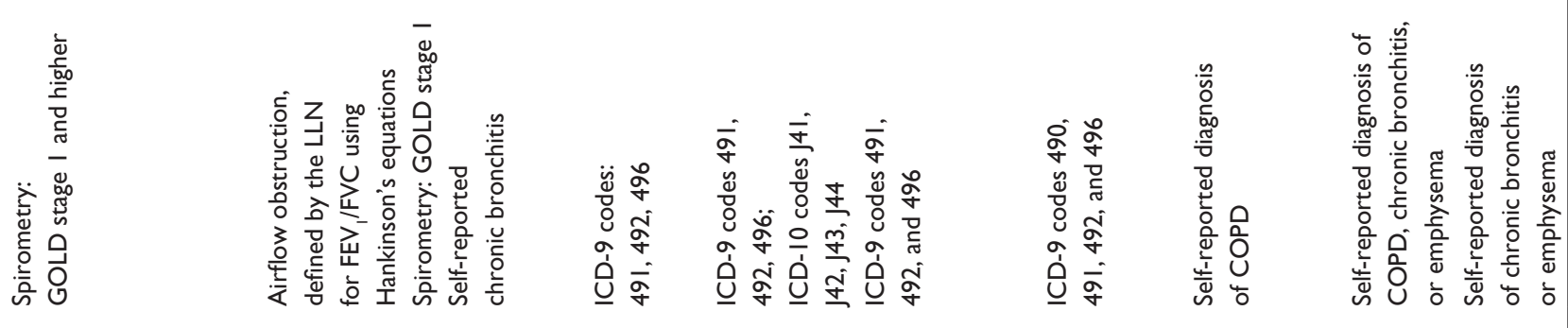

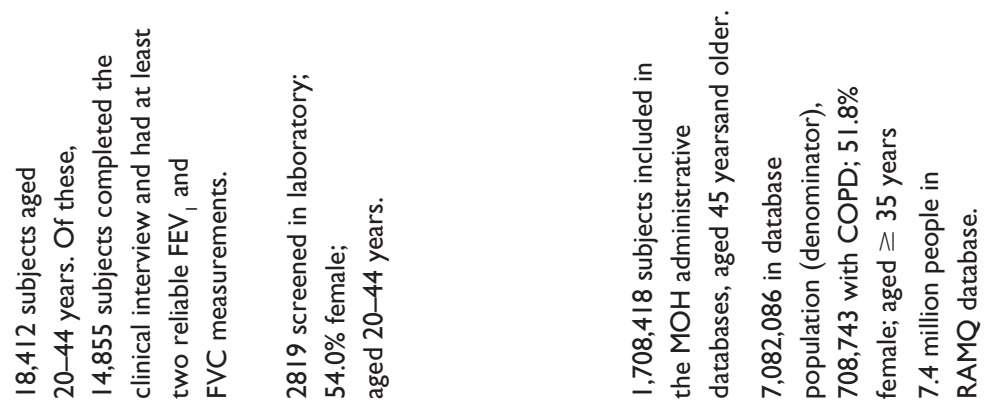

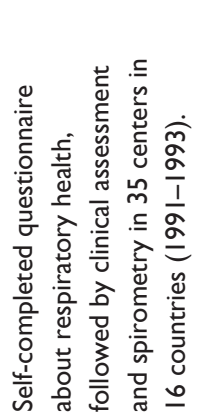

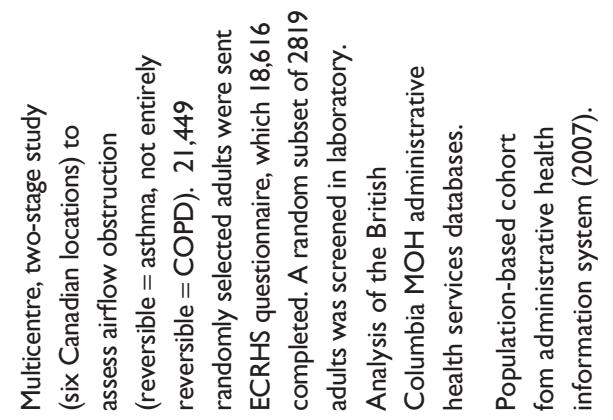

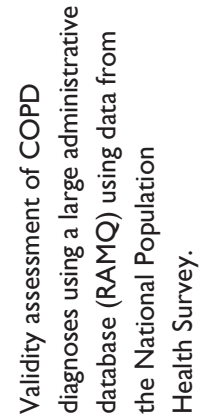

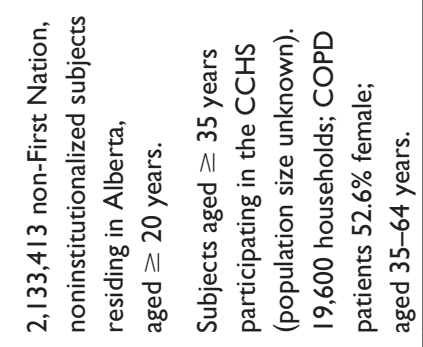

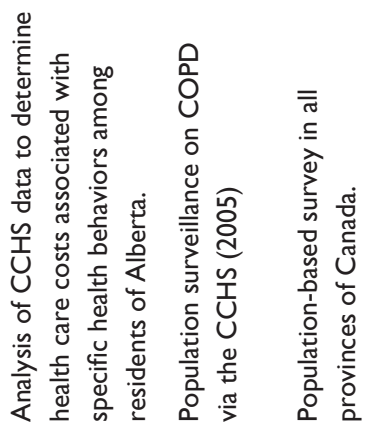

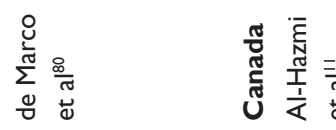

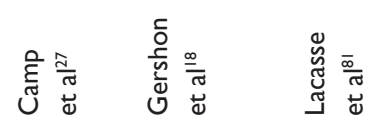

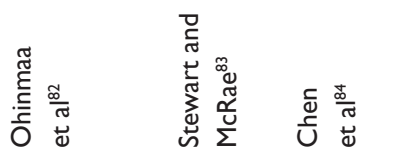




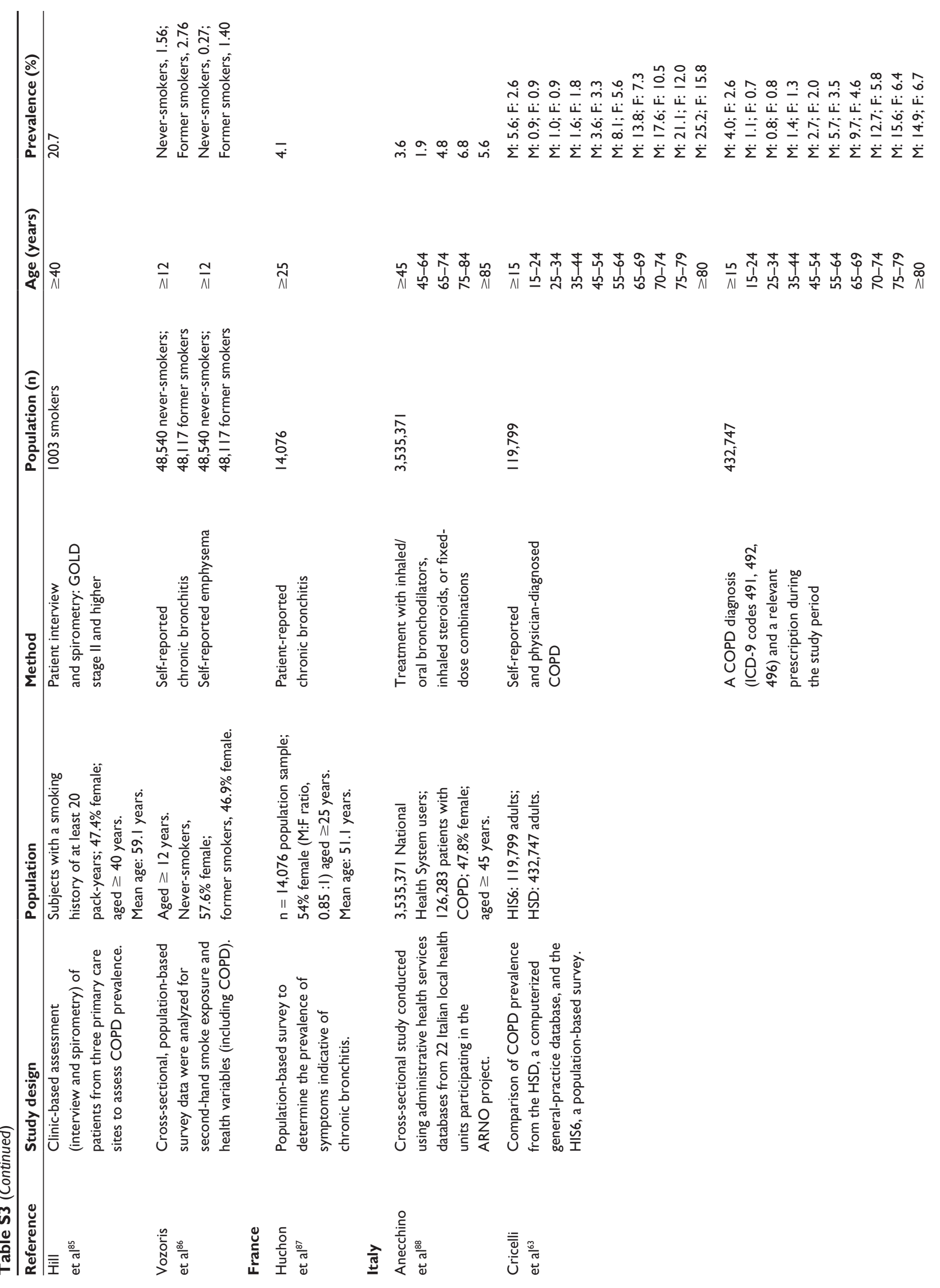




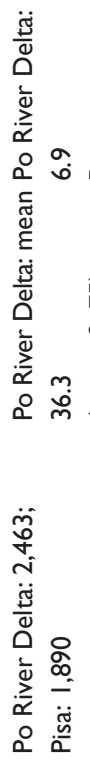

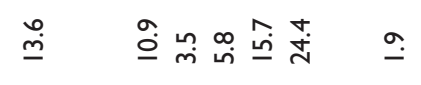

ํㅗㅇ

$\underset{H}{*}$

$\stackrel{m}{0} \quad \pm$

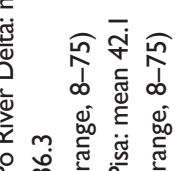

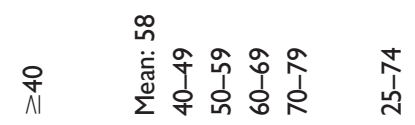

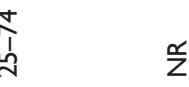

$\frac{1}{3} \quad \stackrel{ }{N}$

N)

$\stackrel{\mathbb{Z}}{\stackrel{m}{\widetilde{d}}}$

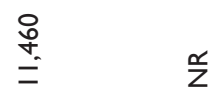

$\underset{\substack{8 \\ i}}{1}$

$\stackrel{\infty}{\hat{h}} \quad \stackrel{\infty}{6}$

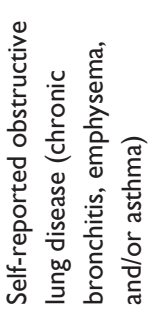

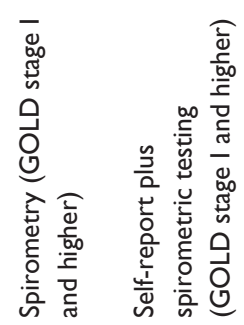

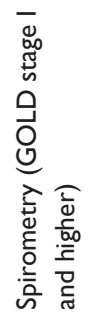

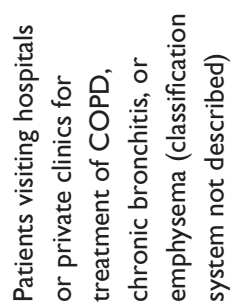

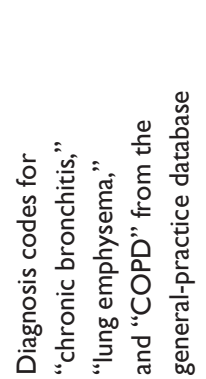
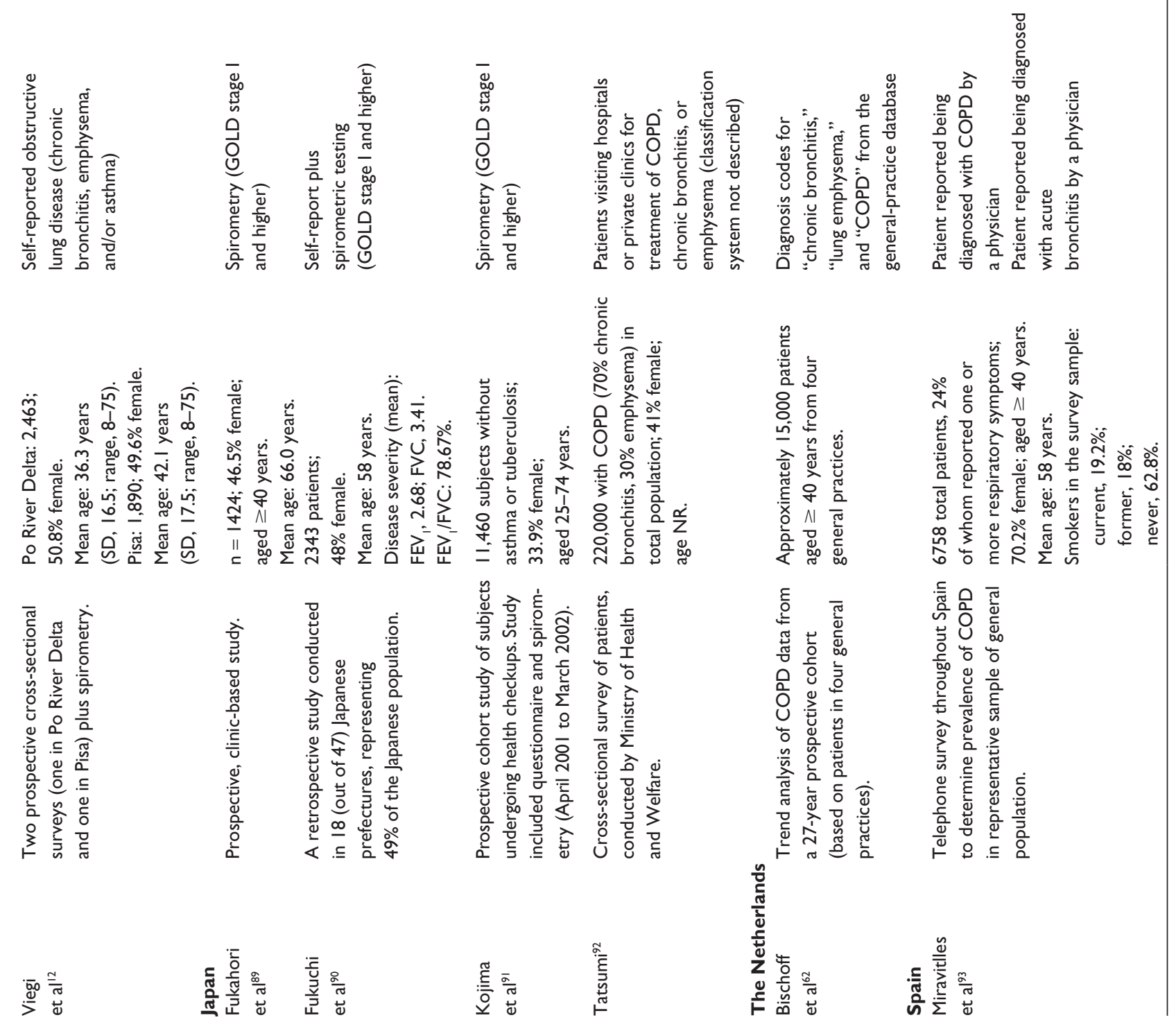


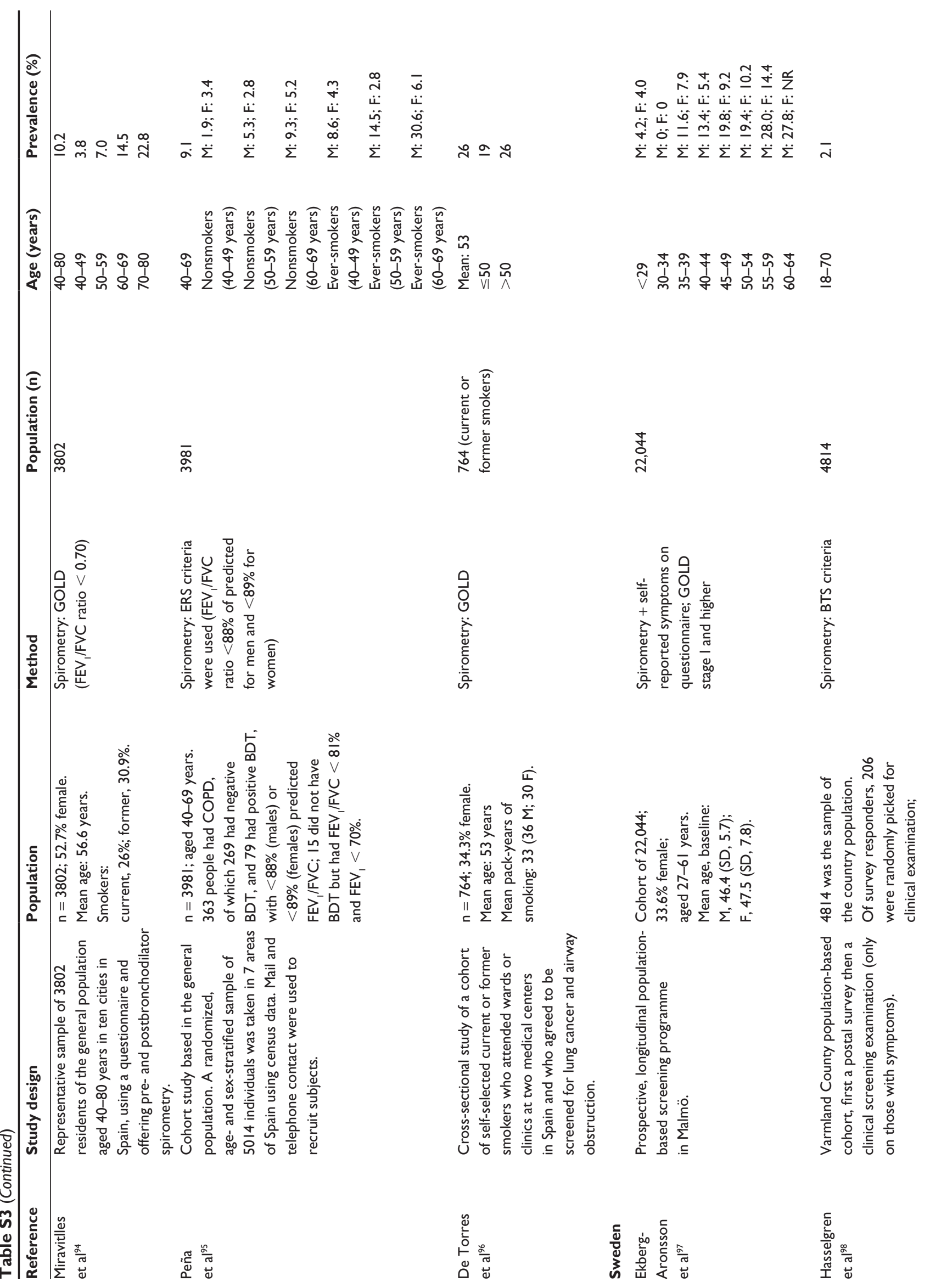




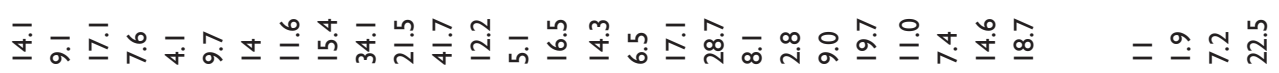

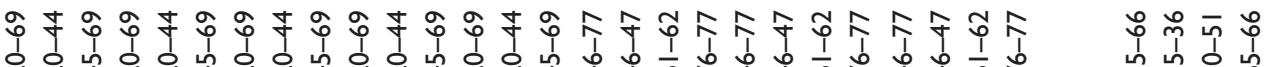

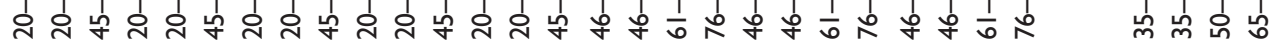

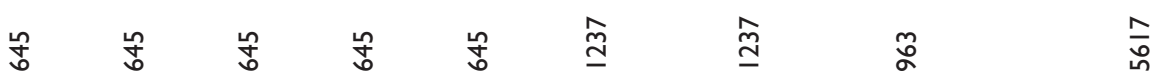

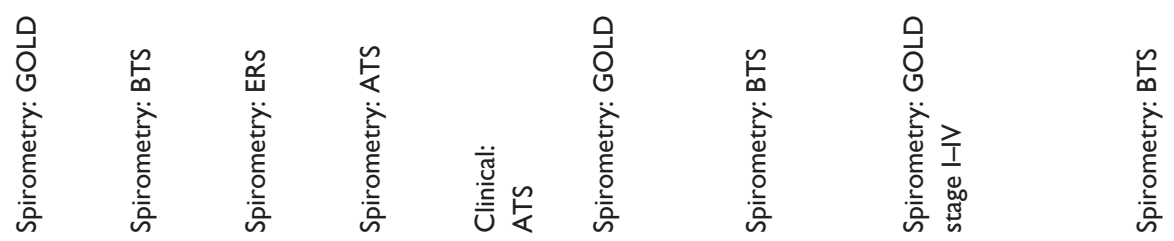

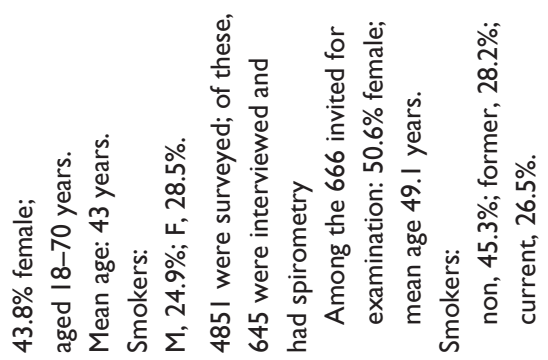

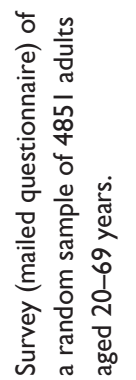

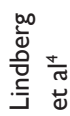
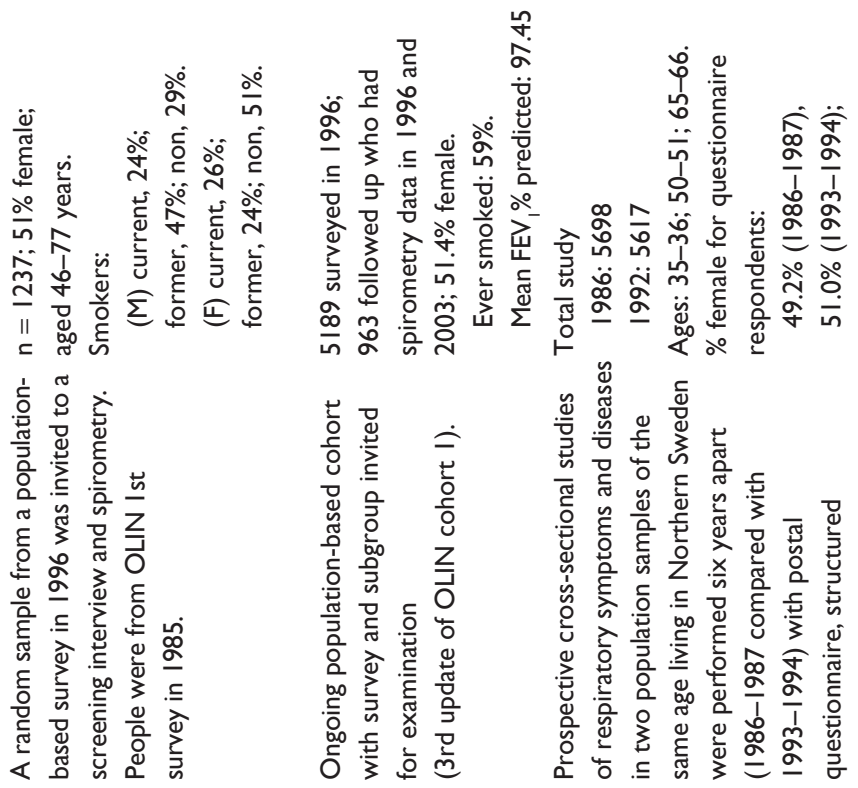

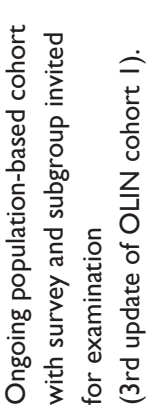

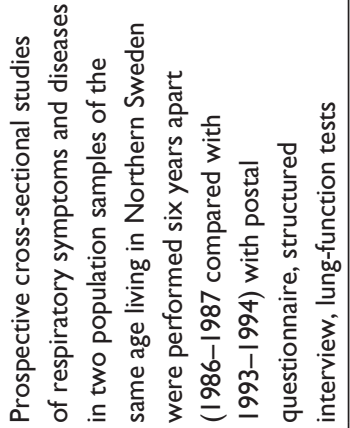

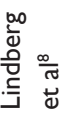

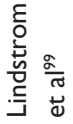




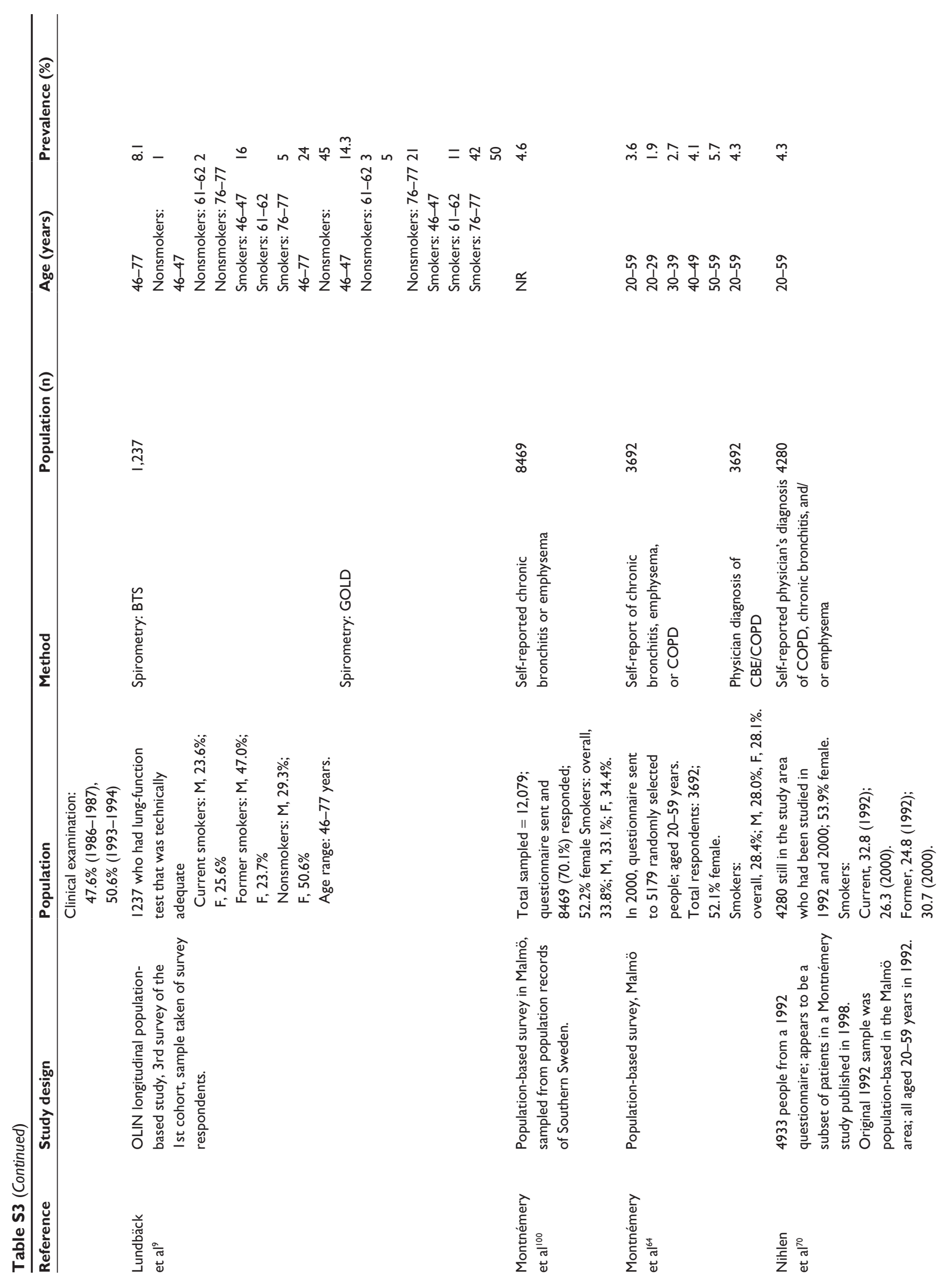




\begin{tabular}{|c|c|c|c|c|}
\hline Oे. & $\begin{array}{l}\stackrel{\circ}{\sim} \\
\ddot{\sim} \\
\stackrel{\sim}{\sim} \\
\ddot{\Sigma}\end{array}$ & 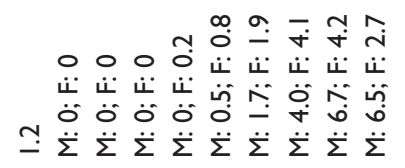 & $\underline{m}$ & 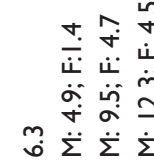 \\
\hline 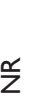 & $\begin{array}{l}\underline{\underline{n}} \\
\underline{b}\end{array}$ & 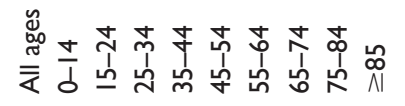 & 号 & 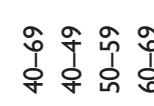 \\
\hline 芯 & $\begin{array}{l}\hat{o} \\
\stackrel{0}{0} \\
\underline{\infty}\end{array}$ & $\begin{array}{l}8 \\
\frac{8}{\sigma} \\
\frac{\dot{n}}{\sigma}\end{array}$ & Oे & กี \\
\hline
\end{tabular}
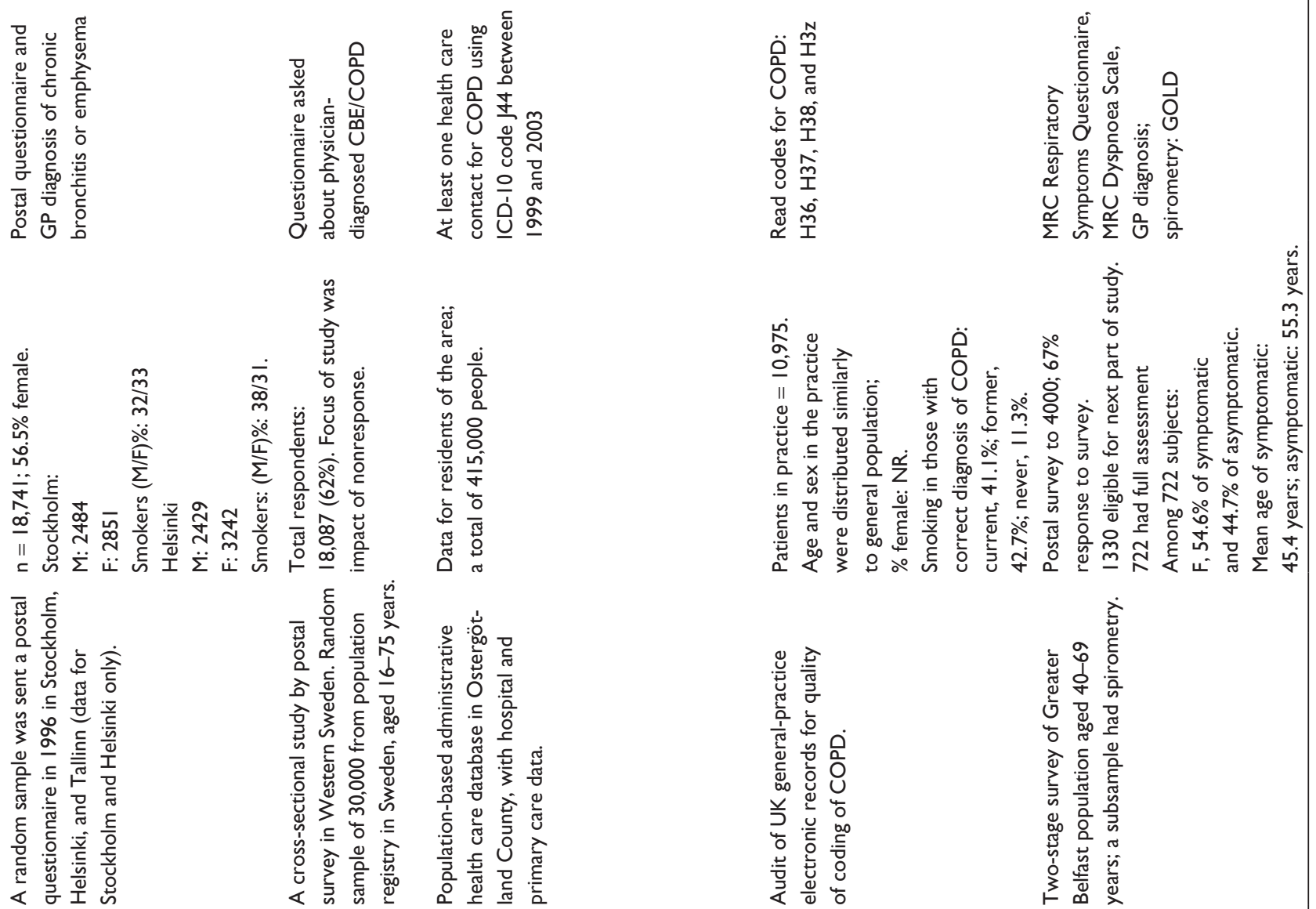

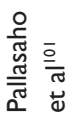

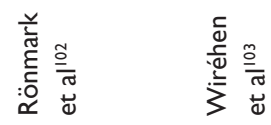

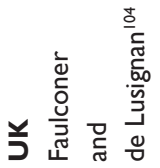

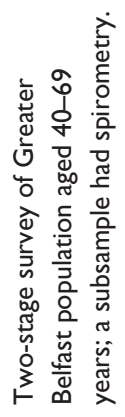




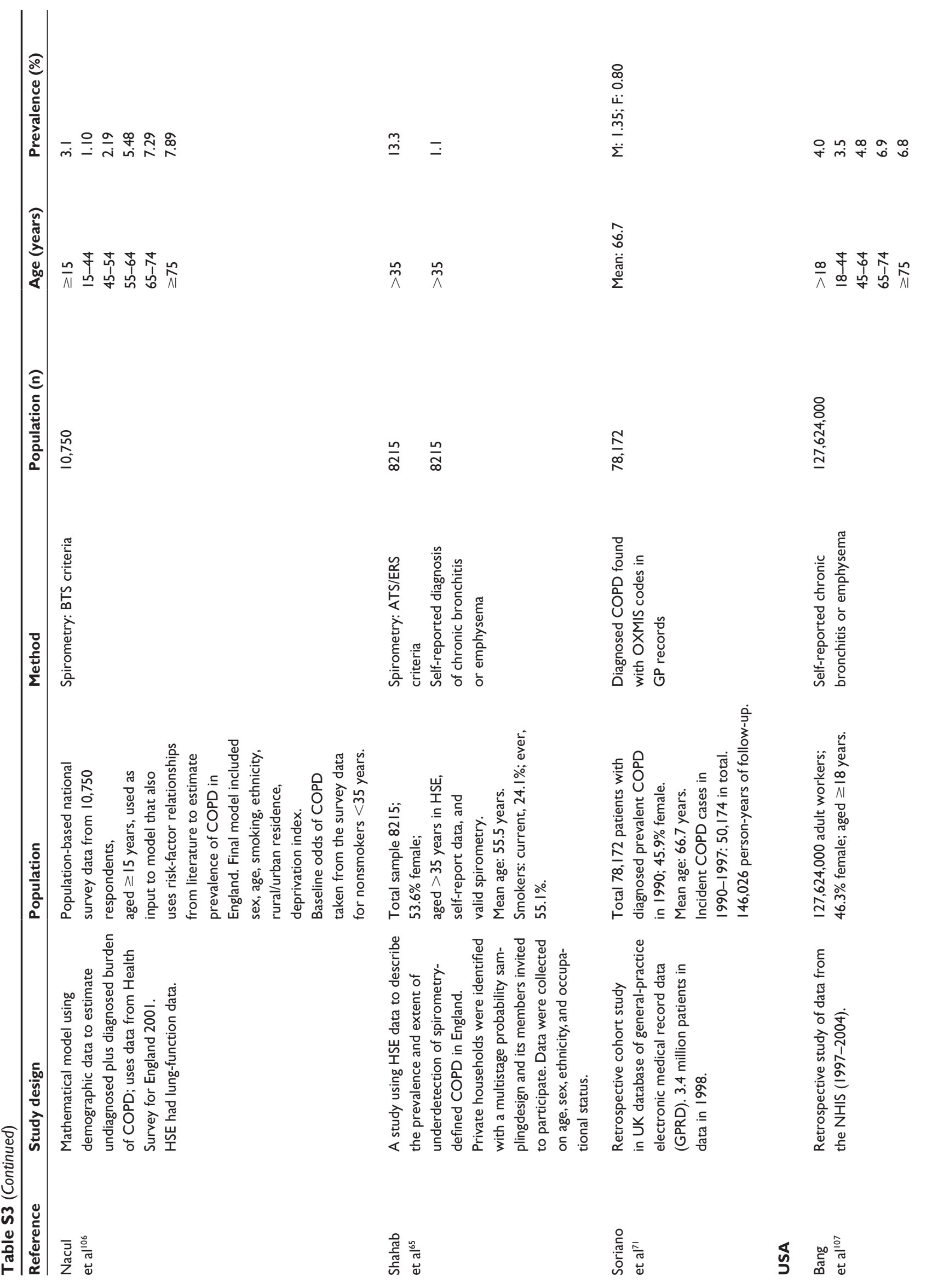




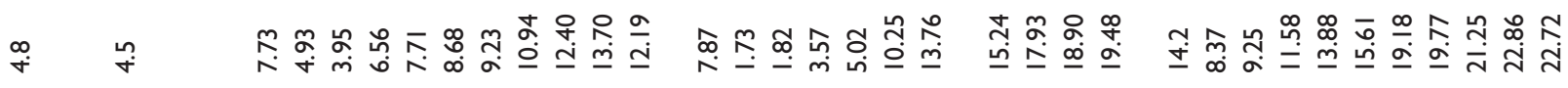

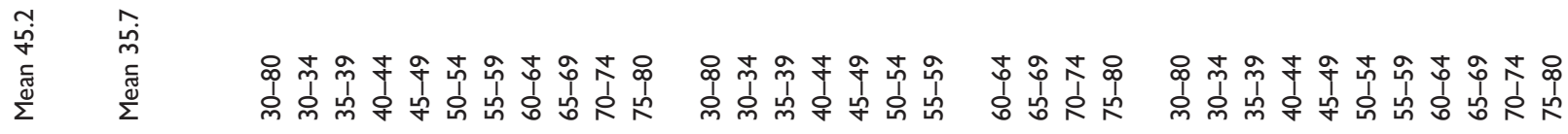

$\begin{array}{lll}\stackrel{\infty}{\infty} & \bar{\infty} & \infty \\ \stackrel{\infty}{m} & \stackrel{\infty}{\sim} & \stackrel{\infty}{\infty}\end{array}$

$\underset{\substack{0 \\ \hdashline}}{\infty}$

$\stackrel{\infty}{\infty}$

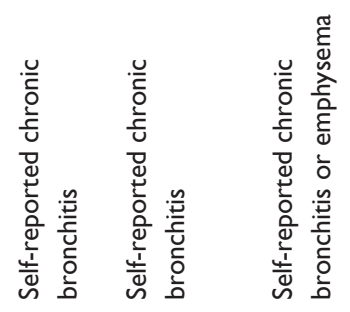

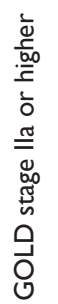

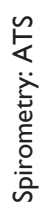

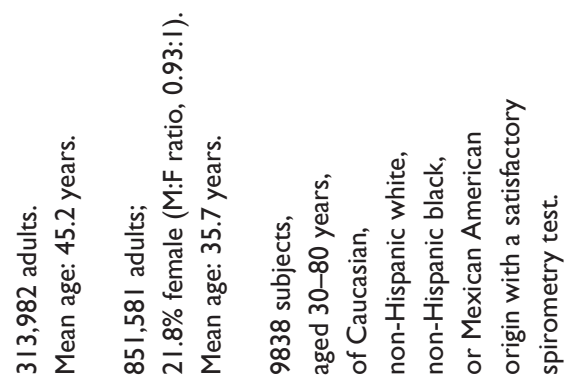

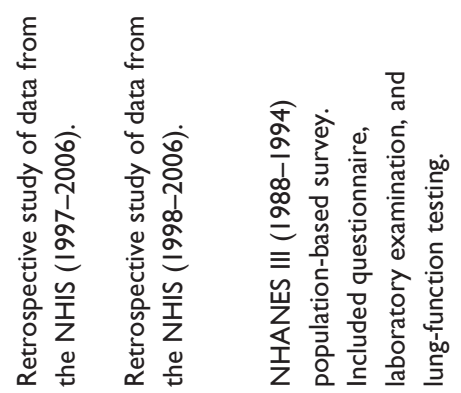

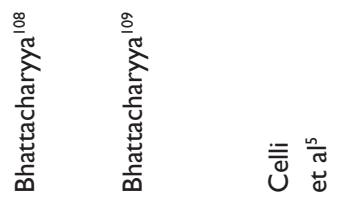




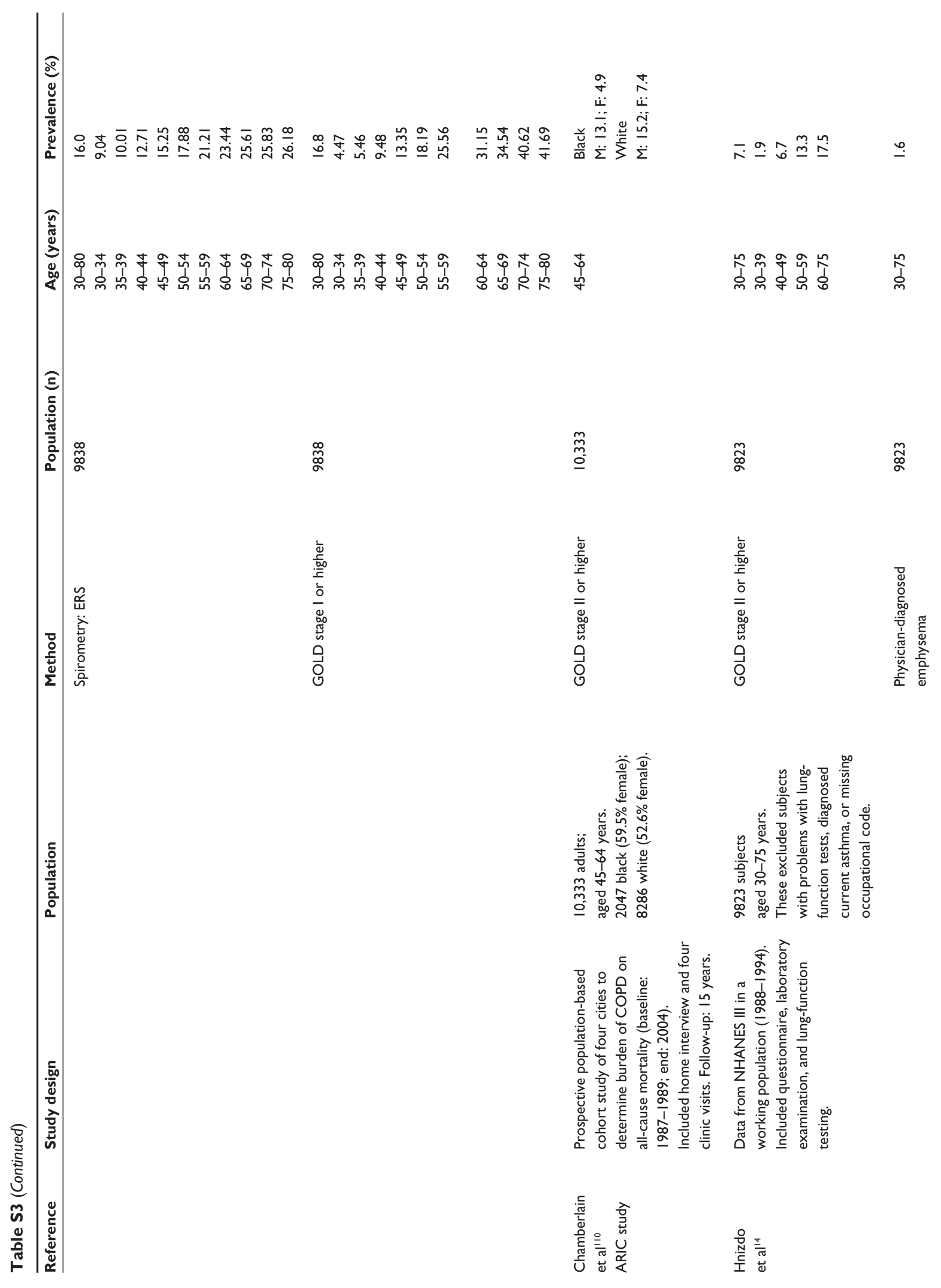




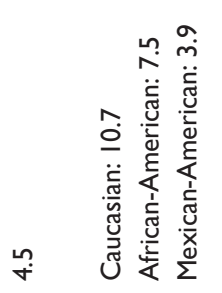

$\begin{array}{ll}n & n \\ \grave{j} & \stackrel{p}{p}\end{array}$

$\stackrel{\Re}{\sim} \underset{\sim}{*}$

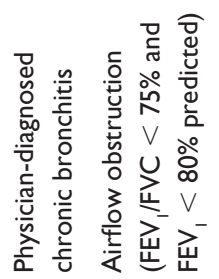

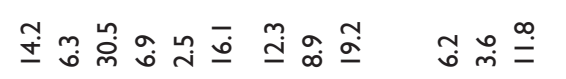

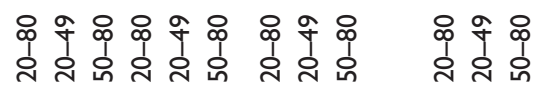

○ ஒ

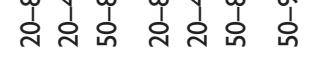

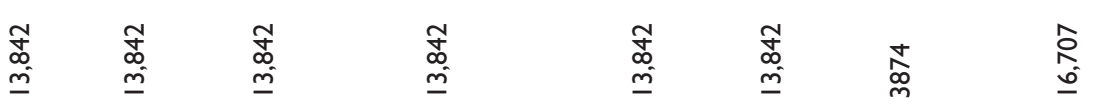
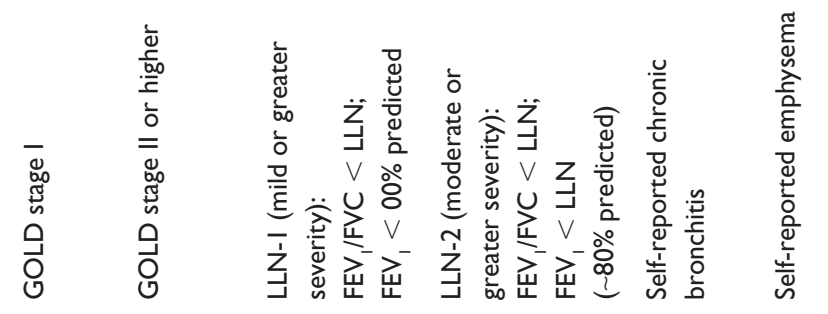

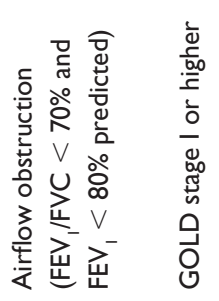
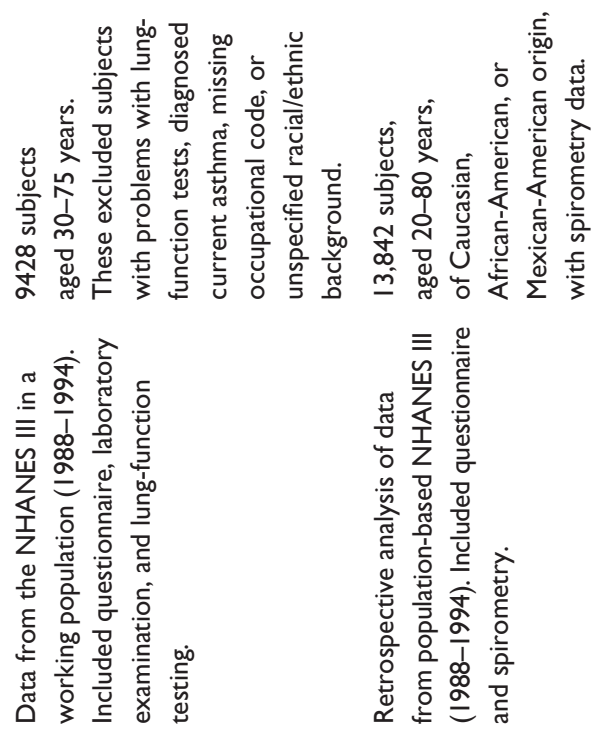

亭

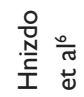

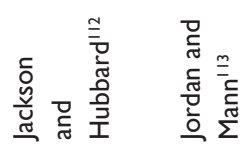

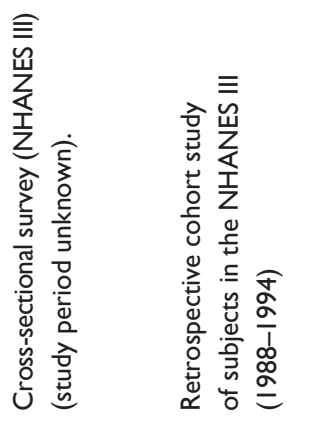




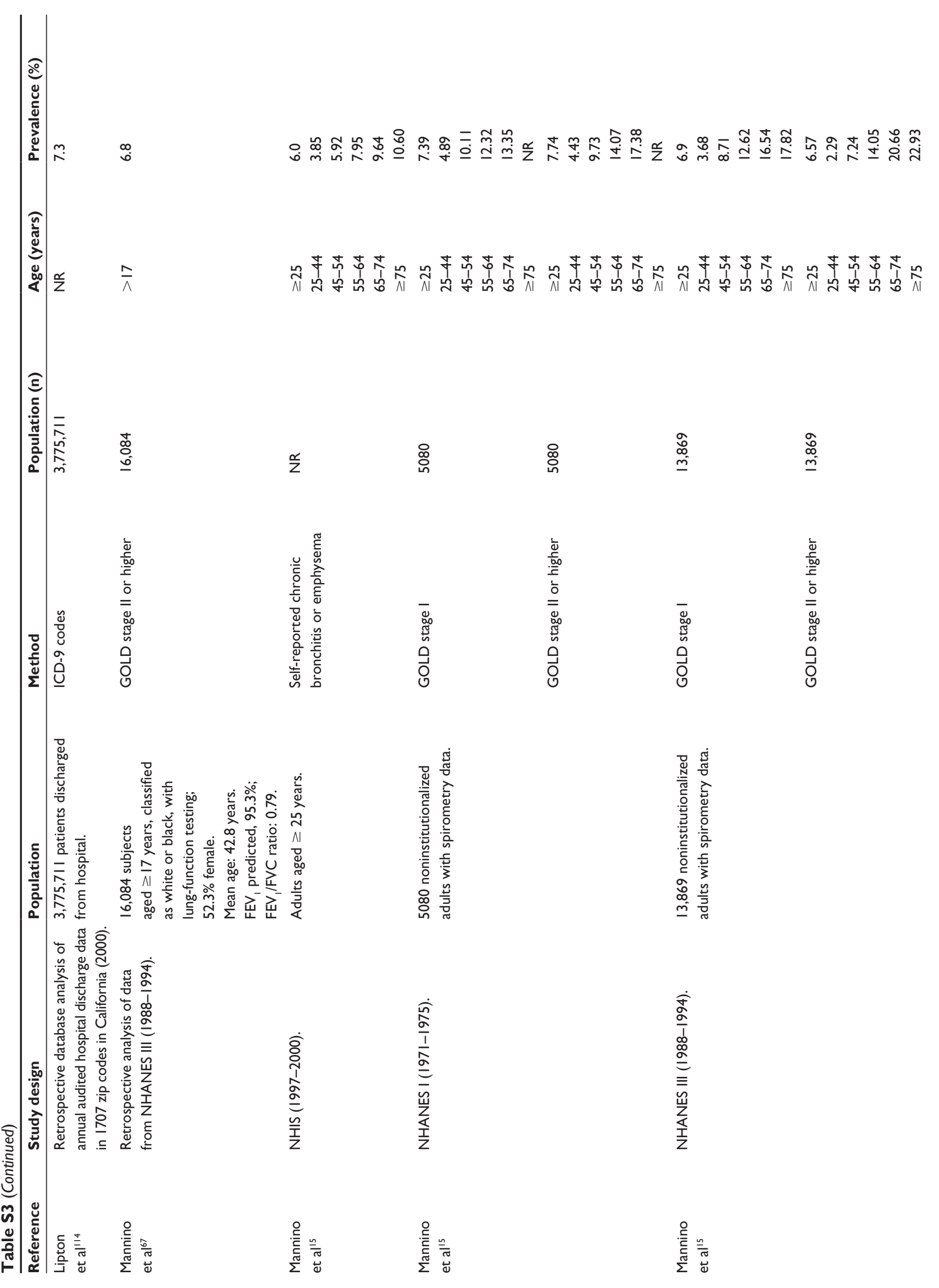




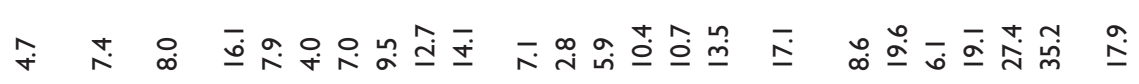

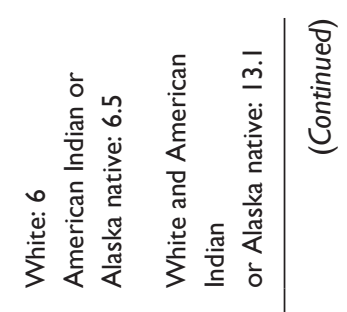

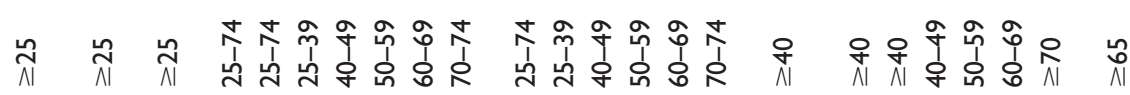

$\stackrel{\alpha}{z}$

石 :

苞

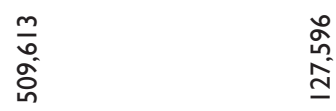

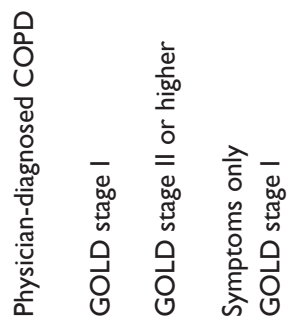

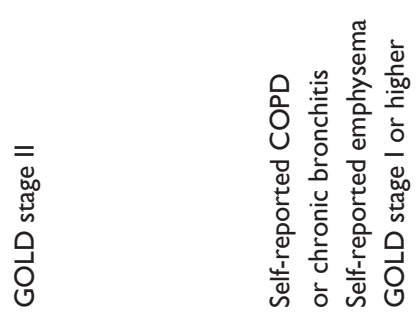

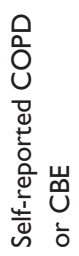
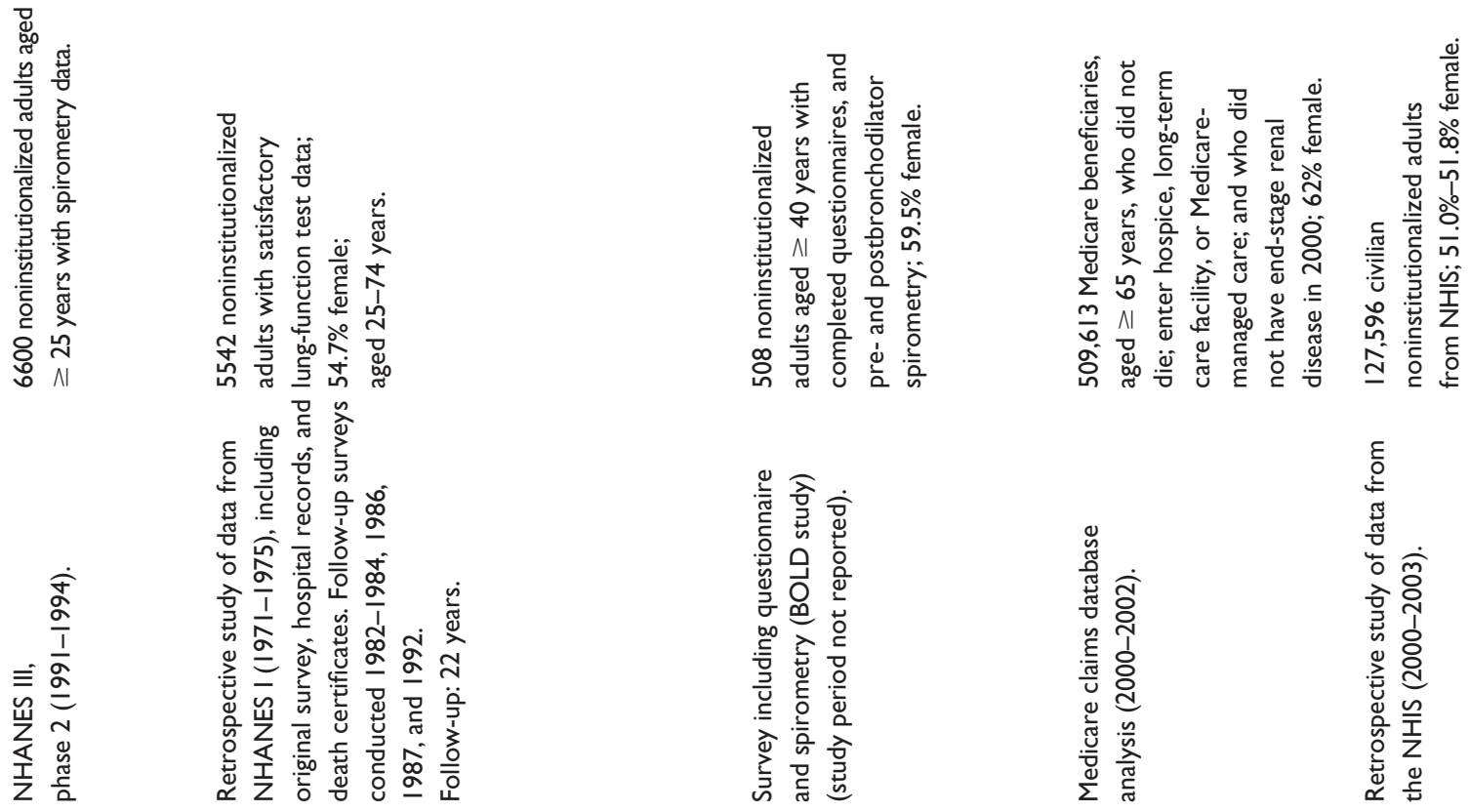

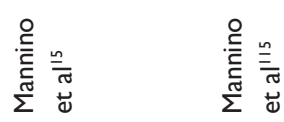

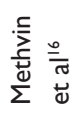

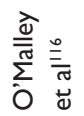

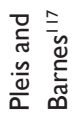




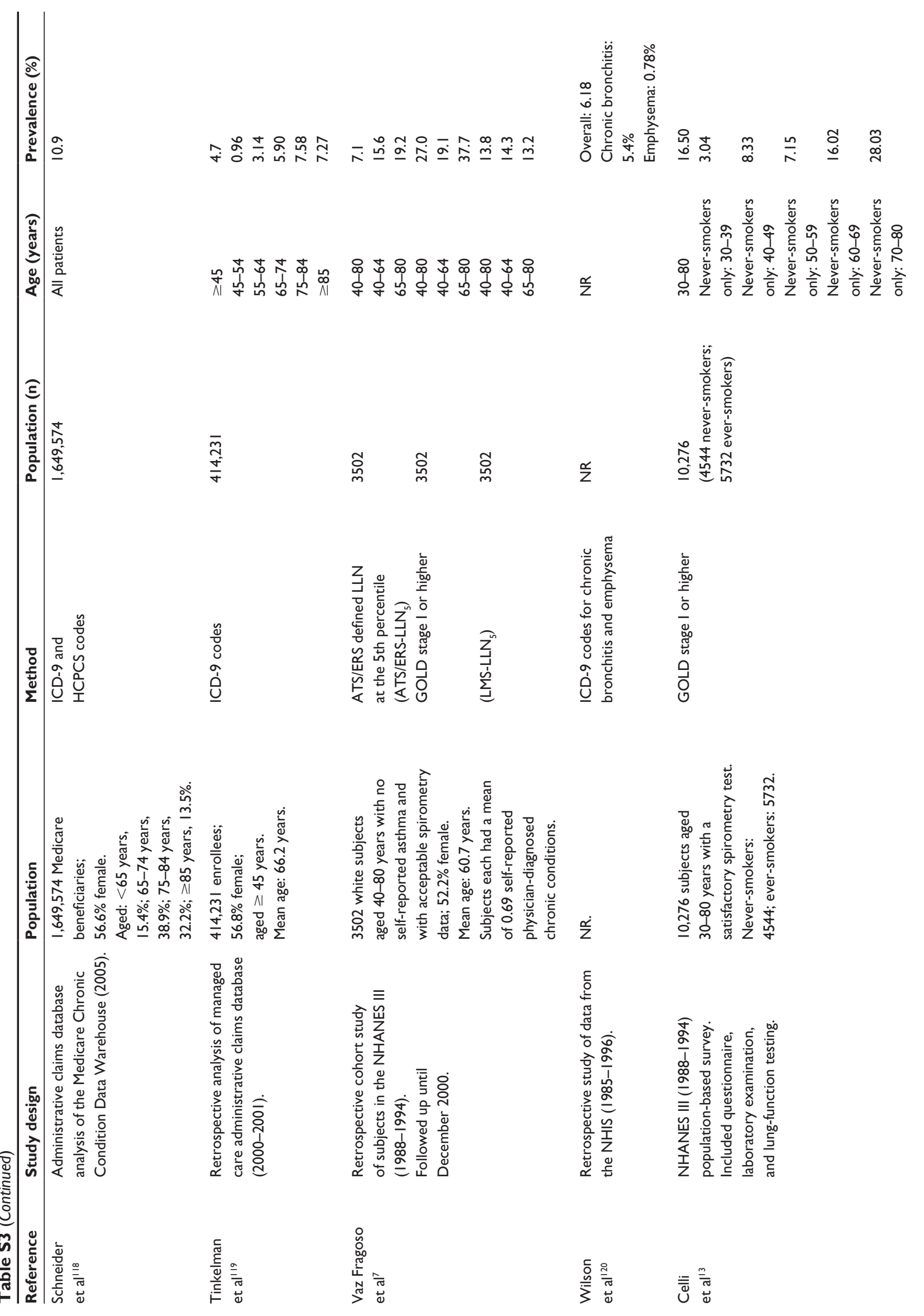




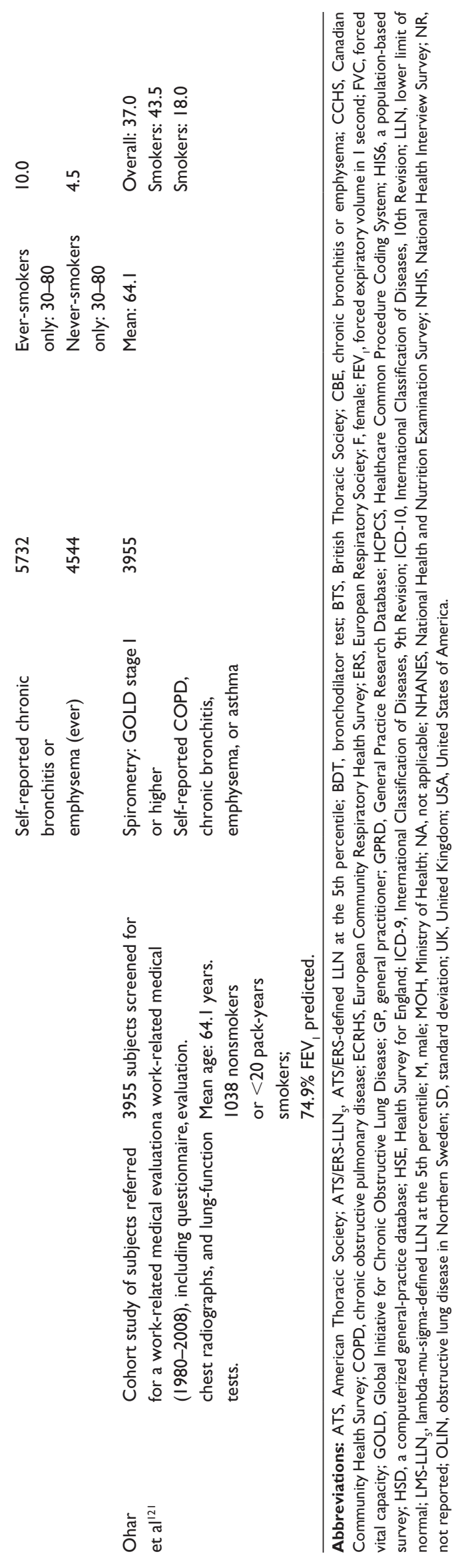




\section{Publish your work in this journal}

The International Journal of COPD is an international, peer-reviewed journal of therapeutics and pharmacology focusing on concise rapid reporting of clinical studies and reviews in COPD. Special focus is given to the pathophysiological processes underlying the disease, intervention programs, patient focused education, and self management protocols.

This journal is indexed on PubMed Central, MedLine and CAS. The manuscript management system is completely online and includes a very quick and fair peer-review system, which is all easy to use. Visit http://www.dovepress.com/testimonials.php to read real quotes from published authors.

Submit your manuscript here: http://www.dovepress.com/international-journal-of-copd-journal 